\title{
An Observational and Modeling Study of Mesoscale Air Masses with High Theta-E ${ }^{\mathbb{O}}$
}

\author{
WOLFGANG HANFT AND AdAm L. Houston \\ Department of Earth and Atmospheric Sciences, University of Nebraska-Lincoln, Lincoln, Nebraska
}

(Manuscript received 20 December 2017, in final form 17 May 2018)

\begin{abstract}
Typically, the cool side of an airmass boundary is stable to vertical motions due to its associated negative buoyancy. However, under certain conditions, the air on the cool side of the boundary can undergo a transition wherein it assumes an equivalent potential temperature and surface-based convective available potential energy that are higher than those of the air mass on the warm side of the boundary. The resultant air mass is herein referred to as a mesoscale air mass with high theta-e (MAHTE). Results are presented from an observational and mesoscale modeling study designed to examine MAHTE characteristics and the processes responsible for MAHTE formation and evolution. Observational analysis focuses on near-surface observations of an MAHTE in northwestern Kansas on 20 June 2016 collected with a Combined Mesonet and Tracker. The highest equivalent potential temperature is found to be $15-20 \mathrm{~K}$ higher than what was observed in the warm sector and located $2-5 \mathrm{~km}$ on the cool side of the boundary. This case was also modeled using WRF-ARW to examine the processes involved in MAHTE formation that could not be inferred through observations alone. Model analysis indicates that differential vertical advection of equivalent potential temperature across the boundary is important for simulated MAHTE formation. Specifically, deeper vertical mixing/advection in the warm sector reduces moisture (equivalent potential temperature), while vertical motion/mixing is suppressed on the cool side of the boundary, thereby allowing largely unmitigated insolation-driven increases in equivalent potential temperature. Model analysis also suggests that surface moisture fluxes were unimportant in simulated MAHTE formation.
\end{abstract}

\section{Introduction}

Air masses behind thunderstorm gust fronts and synoptic-scale airmass boundaries are typically stable to vertical motion and are usually more conditionally stable (lower CAPE) than the ambient (warm side) air mass. However, narrow regions immediately on the cool side of airmass boundaries can experience increases in equivalent potential temperature that render these regions more conditionally unstable than the corresponding warm-side air mass (e.g., Rasmussen et al. 2000; Gilmore and Wicker 2002; Guyer and Ewald 2004; Groenemeijer et al. 2011). This localized area will be referred to as a mesoscale air mass with high theta-e (MAHTE). MAHTEs are typically

\footnotetext{
Supplemental information related to this paper is available at the Journals Online website: https://doi.org/10.1175/MWR-D-170389.s1.
}

Corresponding author: Wolfgang Hanft, wolfganghanft@huskers. unl.edu meso- $\gamma$ scale in width (Rasmussen et al. 2000; Gilmore and Wicker 2002; Groenemeijer et al. 2011) and may extend along significant lengths of synoptic boundaries; however, observations presented in prior work were insufficient to reveal the exact scales of MAHTEs. Nevertheless, existing evidence suggests that their small size places them at the limits of resolution of conventional observation networks and most current numerical weather prediction models. Moreover, since the processes responsible for their formation are not fully understood, conceptual models and forecasting heuristics have not been developed. This study aims to examine MAHTE characteristics using data collected within a MAHTE and to examine the possible mechanisms for MAHTE formation through mesoscale modeling.

Deep convection forming on or near airmass boundaries associated with MAHTEs could be significantly influenced by the attendant higher CAPE. A possible example of this influence is the Aurora, Nebraska, supercell of 22 June 2003 (Guyer and Ewald 2004). This storm initiated in a region of confluence on the warm 
side of a preexisting outflow boundary associated with an air mass that showed characteristics of a MAHTE (Guyer and Ewald 2004). Specifically, the highest values of $\theta_{e}$ were located at the leading edge of the preexisting outflow, which Guyer and Ewald (2004) attributed to the combination of "moisture pooling" on the cool side of the boundary and insolation across the entire region. CAPE was observed to be $500-1000 \mathrm{~J} \mathrm{~kg}^{-1}$ higher within the MAHTE (Guyer and Ewald 2004). Rapid intensification of storms was noted as they crossed the preexisting outflow boundary and traveled across the MAHTE (Guyer and Ewald 2004; Wakimoto et al. 2004). The storm that passed near Aurora, Nebraska, produced a record-breaking 7-in. hailstone.

Another MAHTE occurred on 2 June 1995 in the Texas Panhandle. Like the 22 June 2003 MAHTE, this MAHTE developed in association with a preexisting outflow boundary. Observations of the MAHTE were collected by mobile mesonets involved in the Verification of the Origins of Rotation in Tornadoes Experiment (VORTEX; Rasmussen et al. 1994). Mobile mesonets transected this preexisting outflow boundary and recorded locally higher water vapor mixing ratio and $\theta_{e}$ directly on the cool side of the boundary relative to the warm air mass (Rasmussen et al. 2000). Data from soundings released on each side of the boundary suggested that vertical mixing was occurring through greater depths on the warm side of the boundary than on the cool side (Gilmore and Wicker 2002), and while the cause of the higher water vapor mixing ratio directly along the cool side of the boundary was not known, the shallower mixing in the outflow air mass would have theoretically allowed for less dry-air entrainment into the cold pool, compared to the environmental air mass. This would allow water vapor mixing ratios to remain higher in the outflow air mass. Storms in the afternoon of 2 June 1995 initiated in the warm sector, rapidly strengthened after moving across the boundary, and produced several significant tornadoes (Rasmussen et al. 2000).

MAHTEs can also form along warm fronts. An example of this occurred on the cool side of a warm front in central England on 28 July 2005 (Groenemeijer et al. 2011). Dewpoint temperatures directly on the cool side of the warm front were higher than those observed in the warm air mass and, despite lower temperatures, resulted in a localized maximum in $\theta_{e}$ and CAPE directly on the cool side of the warm front (Groenemeijer et al. 2011). Groenemeijer et al. (2011) hypothesized that the differences in moisture and $\theta_{e}$ across the front were attributable to differences in insolation and mixing. Clearing south of the warm front resulted in deeper convective mixing, which reduced dewpoint temperatures in the warm air mass. Cloud cover remained along and north of the warm front into the afternoon, reducing insolation and therefore reducing the vertical depth of convective mixing north of the warm front. Groenemeijer et al. (2011) speculate that this, combined with an easterly wind off the ocean, kept dewpoint temperatures high and resulted in the formation of a MAHTE by the afternoon.

In the work presented here, analysis of observational and modeling-based datasets forms the basis of an examination of the structure and formation of MAHTEs. This article proceeds in section 2 with a review of theoretical processes responsible for changes in $\theta_{e}$. Results from the observational component of this work are presented in section 3 and from the modeling component in section 4. A discussion of processes leading to MAHTE formation appears in section 5. Conclusions are presented in section 6 .

\section{Background}

Changes in $\theta_{e}$ that ultimately lead to MAHTE formation can be described through the rate of change of entropy. Entropy and $\theta_{e}$ are typically conserved in the absence of irreversible processes. The most dominant of these irreversible processes that result in an increase in entropy is diabatic heating at constant pressure, primarily through heat fluxes driven by insolation (Peixoto et al. 1991; Goody 2000; Raymond 2013). After diabatic processes, increases in entropy due to irreversible processes are dominated by phase transitions of water (Pauluis and Held 2002). This includes the evaporation of rain in unsaturated air (Emanuel 1994); nonequilibrium phase changes; and evaporation from either a body of water or land surface, where the heat capacity of the storage term is large enough that energy for evaporation is drawn from the body of water or land surface, rather than being removed from the atmosphere (Emanuel 1994; Raymond 2013). For evaporation to result in an increase in entropy, the temperature at which this phase transition occurs is important. Evaporation occurring at warmer temperatures (i.e., temperatures comparable to those typically at cloud base or in the boundary layer) results in an entropy increase, while evaporation at colder temperatures, like those found at cloud tops, does not (Bannon 2002; Pauluis and Held 2002). Other irreversible processes that can result in an increase in entropy include the diffusion of water vapor into the system, frictional dissipation, and molecular diffusion (Peixoto et al. 1991; Raymond 2013). Most of these processes either result in an increase in temperature of the system or in an increase in water vapor content and therefore an increase in entropy (Raymond 2013). 
Because equivalent potential temperature is derived from entropy, any increase in entropy will result in an increase in equivalent potential temperature. In an Eulerian frame of reference, $\theta_{e}$ tendency would, of course, also depend upon advection of $\theta_{e}$ and thus the advection of variables on which $\theta_{e}$ depends (e.g., moisture and temperature).

Since MAHTEs evolve on the cool side of airmass boundaries, it is important to consider the processes endemic to airmass boundaries that might lead to increases in $\theta_{e}$. Air masses in the immediate vicinity of thunderstorm gust fronts and even boundaries exhibiting synoptic along-boundary scales (e.g., cold fronts) can behave similar to density currents (Charba 1974; Simpson 1987). The coldest air within a density current is typically located near the surface within the head (usually within $5 \mathrm{~km}$ of the front), while the strongest surface winds are located directly behind the head beneath the turbulent wake (Grant and van den Heever 2016; Lowe et al. 2002), with average wind speed in this region $30 \%-50 \%$ higher than the velocity of the density current (Lowe et al. 2002). Within the cold pool head, wind speeds are $\sim 10 \%$ higher than the speed of the density current (Lowe et al. 2002).

Faster winds in the density current result in convergence near the front. Higher values of moisture are often found collocated with areas of convergence, suggesting that moisture convergence may be important for MAHTE formation. However, moisture convergence cannot directly increase moisture content (Markowski and Richardson 2010). Instead, moisture convergence could lead to an increase in the depth of moisture, thereby insulating the air mass from the deleterious impact of downward advection-mixing of lower moisture from above the convective boundary layer (Markowski and Richardson 2010). This process is one mechanism by which the cold side of fronts can have higher $\theta_{e}$ by the early afternoon hours.

The characteristic wind speed, temperature, and moisture within a density current can also impact surface fluxes. Irreversible changes to entropy and thus $\theta_{e}$ can occur through surface fluxes of energy and moisture. Energy is primarily transported from the surface to the atmosphere through two mechanisms: sensible heat flux and latent heat flux. Adapted from Yokoi et al. (2014), sensible heat flux can be expressed as SHF = $\rho c_{p} C U\left(\theta_{\mathrm{sfc}}-\theta_{\text {air }}\right)$, and latent heat flux can be expressed as LHF $=\rho L_{v} C U\left(q_{\mathrm{sfc}}-q_{\mathrm{air}}\right)$, where $\rho$ is the surface air density, $c_{p}$ is the specific heat of moist air at constant pressure, $L_{v}$ is the latent heat of vaporization of water, $C$ is the bulk transfer coefficient of heat and moisture, $U$ is the surface wind speed, $\theta$ is the potential temperature of the surface or air, and $q$ is the specific humidity of the surface or air. It is clear that surface heat flux scales directly with the temperature difference between the air and the surface and with wind speed. Similarly, latent heat flux scales directly with humidity difference between the surface and air and with wind speed. Moisture flux $\left(F_{\text {water }}\right)$ can also produce irreversible changes to entropy and is related to latent heat flux: $F_{\text {water }}=\mathrm{LHF} / L_{v}$.

For tropical thunderstorm cold pools, the temperature difference between the cold pool and the ocean surface has been found to be much more important than the impact of wind speed on surface sensible heat flux (Young et al. 1995). However, prior work indicates that wind speed is the primary cause of increased surface latent flux in cold pools relative to ambient surface latent heat flux (Young et al. 1995; Yokoi et al. 2014; Schlemmer and Hohenegger 2016; Skyllingstad and de Szoeke 2015); differences in moisture between the air and surface were found to be of secondary importance. Moisture fluxes have been found to account for $30 \%$ of the moisture anomaly in the cold pool head (Schlemmer and Hohenegger 2016).

Multiple studies of cold pools over tropical oceans have documented examples where rings of moisture are found at the leading edge of thunderstorm cold pools. Tompkins (2001) found that these areas of increased moisture were associated with areas of higher $\theta_{e}$ and CAPE, similar to a MAHTE. Tompkins (2001) attributed this increase in moisture to the evaporation of rain and advection of this initial evaporation-enhanced moisture to the leading edge of the cold pool. However, Langhans and Romps (2015) attributed these moisture rings to surface latent heat flux. As cold pools expand laterally, the absolute instability, which forms as a result of the temperature difference between the surface and the cold pool, can generate turbulent kinetic energy, which intensifies latent heat fluxes from the surface (Ross et al. 2004). These increases in surface latent heat fluxes can maintain any humidity anomaly found in the cold pool head as it spreads, which further acts to reduce vertical mixing impacts on moisture in the cold pool head (Ross et al. 2004).

This goal of this study is to address the characteristics of MAHTEs and the processes responsible for their formation and evolution. MAHTE characteristics will be determined using near-surface observations, while processes responsible for their formation will be examined through high-resolution numerical simulations since these processes in MAHTE formation and evolution cannot be determined from surface observations alone. It is hypothesized that

1) Sensible heat flux increases the temperature within a nascent MAHTE, while latent heat flux, tied principally to stronger winds (relative to ambient conditions), increases the moisture. 
TABLE 1. Information on sensors used on the CoMeT.

\begin{tabular}{llll}
\hline \hline \multicolumn{1}{c}{ Component } & \multicolumn{1}{c}{ Model } & \multicolumn{1}{c}{ Output } & \multicolumn{1}{c}{ Accuracy } \\
\hline RH and slow temperature & Vaisala HMP155A-L-PT & Temp: $-80^{\circ}$ to $+60^{\circ} \mathrm{C}$ & $\begin{array}{l}\text { Temp: } \pm(0.226-0.0028 \times \text { temperature })^{\circ} \mathrm{C} \\
\text { RH: } \pm(1.0+0.008 \times \text { reading }) \% \text { RH } \\
\text { Response time: } 20 \mathrm{~s}\end{array}$ \\
& & RH: $0 \%-100 \%$ & $\pm 0.1^{\circ} \mathrm{C}$ \\
Fast temperature & Campbell Scientific $109 \mathrm{SS}-\mathrm{L}$ & $-40^{\circ}$ to $+70^{\circ} \mathrm{C}$ & Response time: $\left.7.5 \mathrm{~s}(3 \mathrm{~m} \mathrm{~s})^{-1}\right)$ \\
& Thermistor & $500-1100 \mathrm{hPa}$ & $\pm 0.25 \mathrm{hPa}$ \\
Pressure & Vaisala PTB210 & WS: $0-100 \mathrm{~m} \mathrm{~s}^{-1}$ & WS: $\pm 1 \%$ \\
Wind & RM Young 05103-L-PT & WD: $00^{\circ}-360^{\circ}$ & WD: \pm 3 \\
& & & \\
\hline
\end{tabular}

2) Because vertical advection is suppressed within the cool air of a nascent MAHTE (compared to the ambient environment), downward advection-mixing of low- $\theta_{e}$ air from above the CBL will be smaller (larger) in the nascent MAHTE (ambient environment), ultimately leading to higher (lower) $\theta_{e}$ as solar insolation produces a positive $\theta_{e}$ tendency.

\section{Observational component}

\section{a. Methodology}

The goal of this component is to address the characteristics and structure of an observed MAHTE. A discussion of the processes responsible for MAHTE formation and evolution based on a mesoscale simulation is the focus of the following section. This analysis focuses on a MAHTE that occurred along the cool side of a slowly moving, east-west-oriented, synoptic cold front in northwestern Kansas on 20 June 2016. Four transects of the MAHTE were made between 1900 and 2300 UTC, from roughly $20 \mathrm{~km}$ south of the boundary in the warm air mass to roughly $40 \mathrm{~km}$ north of the boundary in the cool air mass. Near-surface observations of temperature, relative humidity, pressure, and wind velocity were collected using a Combined Mesonet and Tracker (CoMeT). Information on CoMeT sensors can be found in Table 1. These data were transformed to a boundary relative frame of reference following the methodology of Riganti and Houston (2017), where positions of the boundary were taken as the southern edge of the 20-dBZ reflectivity fine line observed by the Goodland, Kansas, Weather Surveillance Radar-1988 Doppler (WSR-88D). Because of the less-defined nature of the boundary at the initial times of the study, the location of the boundary is more approximate during the initial transects, compared to the later transects.

Rapid Refresh (RAP) model point soundings were obtained to examine how the MAHTE would impact other forecast parameters, such as CAPE. CAPE for these modified soundings was calculated using the Sounding and Hodograph Analysis and Research Program in Python
(Harpy; Blumberg et al. 2017). For these modifications, surface observations of temperature and dewpoint temperature in the ambient warm environment $10 \mathrm{~km}$ south of the cold front, and within the MAHTE where the maximum value of $\theta_{e}$ was observed, were used as the modified sounding surface observations. Sounding modifications were done to examine how surface-based convective available potential energy (SBCAPE) differed across the boundary. Examining how the MAHTE modifies the local environment can provide insight into how a local storm would evolve if it were to interact with the MAHTE, allowing for some inference and comparison with past observed cases of MAHTEs.

One important issue with MAHTEs noted previously is that their small areal extent makes observing them with the current National Weather Service surface observation network difficult. During the late afternoon, this MAHTE passed over the Colby, Kansas, automated surface observation station (ASOS). To compare the collected observations of a MAHTE to how an ASOS station would resolve a MAHTE, 20-min data from the Colby, Kansas, ASOS were obtained, and $\theta_{e}$ was calculated for each available time.

\section{b. Results}

\section{1) SYNOPTIC OVERVIEW}

At 1800 UTC 20 June 2016, the east-northeastwest-southwest-oriented cold front was in place over extreme northwestern Kansas and south-central Nebraska (Fig. 1) and was moving slowly to the south. Temperatures of $25^{\circ}-30^{\circ} \mathrm{C}$ were reported in Nebraska, and $31^{\circ}-34^{\circ} \mathrm{C}$ was reported in Kansas. Winds north of the boundary were from the northeast, with southwesterly winds to the south of the boundary. At 1800 UTC, dewpoint temperatures were relatively similar across the cold front. By 0000 UTC 21 June 2016, the surface cold front had progressed slightly farther to the south, with temperatures across central Kansas reaching as high as $36^{\circ} \mathrm{C}$ and temperatures of $26^{\circ}-27^{\circ} \mathrm{C}$ across Nebraska (not shown). Based on the synoptic-scale observations alone, dewpoint temperatures appeared to 


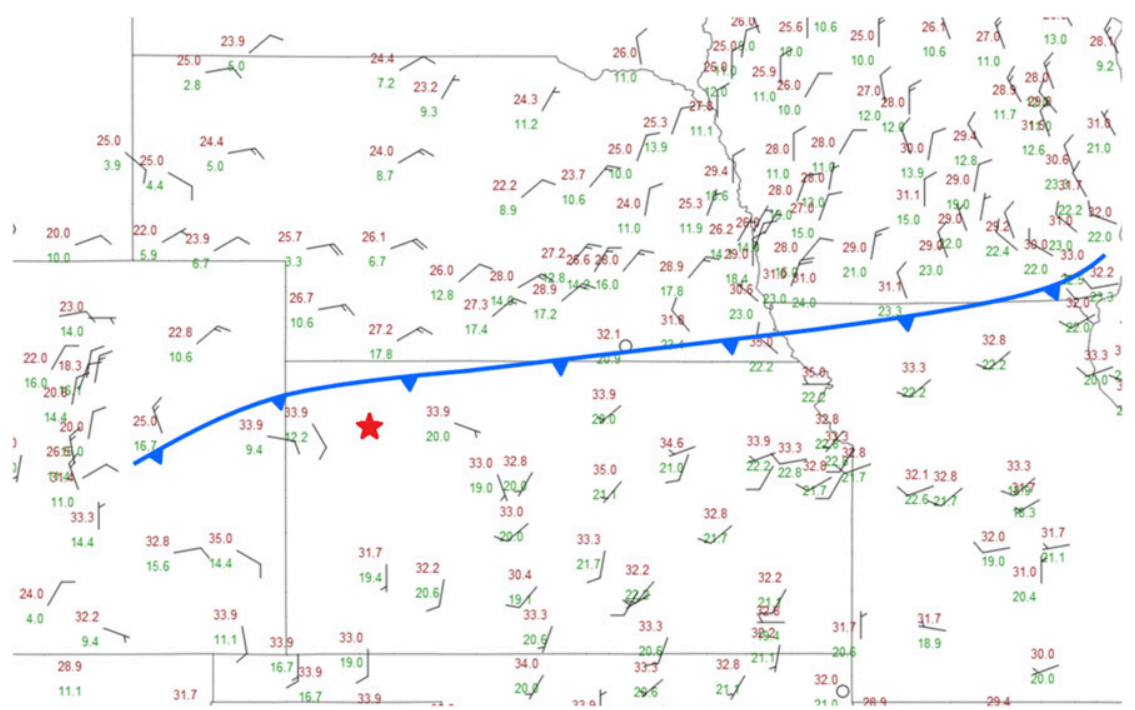

FIG. 1. Synoptic surface observations at 1800 UTC, when surface transects first began. The annotated position of the cold front is indicated in blue, with the location of KCBK (observations unreported on this map at this time) indicated by the red star.

remain near $15^{\circ}-17^{\circ} \mathrm{C}$ across the region. Throughout the day, winds at $850 \mathrm{hPa}$ were out of the south across the entire region. Only scattered clouds were observed (consisting primarily of cumulus humilus); fewer clouds were observed north of the front, though by 2000 UTC 20 June 2016, thunderstorms had formed approximately $150 \mathrm{~km}$ to the north of the cold front (Fig. 2).

\section{2) Characteristics of THE MAHTE}

The location and evolution of the cold front is indicated by the reflectivity fine line in Fig. 2. Transects of the MAHTE were collected roughly perpendicular to the cold front, as indicated by the blue lines in Fig. 2. The goal of these transects was to capture the characteristics of the warm environment, the MAHTE, and the location north of the cold front where $\theta_{e}$ returned to values observed in the warm air mass.

The maximum $\theta_{e}$ during each transect was observed to be approximately $2-6 \mathrm{~km}$ behind the front (Fig. 3). The highest $\theta_{e}(372.9 \mathrm{~K})$ was observed during the first transect at 1942 UTC and steadily decreased during subsequent transects (Fig. 3). The maximum $\theta_{e}$ was observed near the maximum dewpoint temperature in most transects. Similar to $\theta_{e}$, the maximum dewpoint temperature $\left(23.4^{\circ} \mathrm{C}\right)$ was observed during the first transect. The maximum $\theta_{e}$ was $19.8 \mathrm{~K}$ higher than that observed in the warm sector. The higher $\theta_{e}$ relative to the warm sector was due to an increase in dewpoint temperature of $5.8^{\circ} \mathrm{C}$ (Fig. 4) and a corresponding drop in temperature of only $1^{\circ}-2^{\circ} \mathrm{C}$ (Fig. 5). In general, transects revealed that the MAHTE had $\theta_{e}$ values that were $13-20 \mathrm{~K}$ higher than the ambient environment (Fig. 3) and a dewpoint temperature that was $6^{\circ}-8^{\circ} \mathrm{C}$ higher than the ambient environment (Fig. 4). Within the MAHTE, $\theta_{e}$ and dewpoint temperature decreased as the afternoon progressed, though temperature within the MAHTE remained nearly constant despite insolation. On the warm side of the boundary, $\theta_{e}$ remained nearly constant throughout the afternoon.

Throughout the observation period, winds to the south of the boundary were out of the south, while winds to the north of the boundary were out of the northeast (Fig. 6). Winds to the south of the boundary exhibit more intratransect variability than the winds north of the boundary. This is consistent with the notion of stronger and deeper mixing south of the boundary.

The width of a MAHTE is estimated as the distance from the boundary to the point on the cool side where $\theta_{e}$ first returns to the average $\theta_{e}$ observed in the warm sector. This width is estimated by linear interpolation through a least squares regression line, calculated along a segment of each transect from the peak value of $\theta_{e}$ in the MAHTE to the northern end of the transect. Based on this definition, the 20 June 2016 MAHTE had an approximate width of $40-50 \mathrm{~km}$ (Fig. 3). Given the paucity of MAHTE observations, it is difficult to place this width in context. Moreover, widths from prior work are difficult to infer. Using CAPE as a proxy for $\theta_{e}$, it can be inferred that the 2 June 1995 MAHTE was between 15 and $70 \mathrm{~km}$ wide (Gilmore and Wicker 2002), while simulations of the 28 July 2005 MAHTE suggest that it was $25-30 \mathrm{~km}$ wide. 

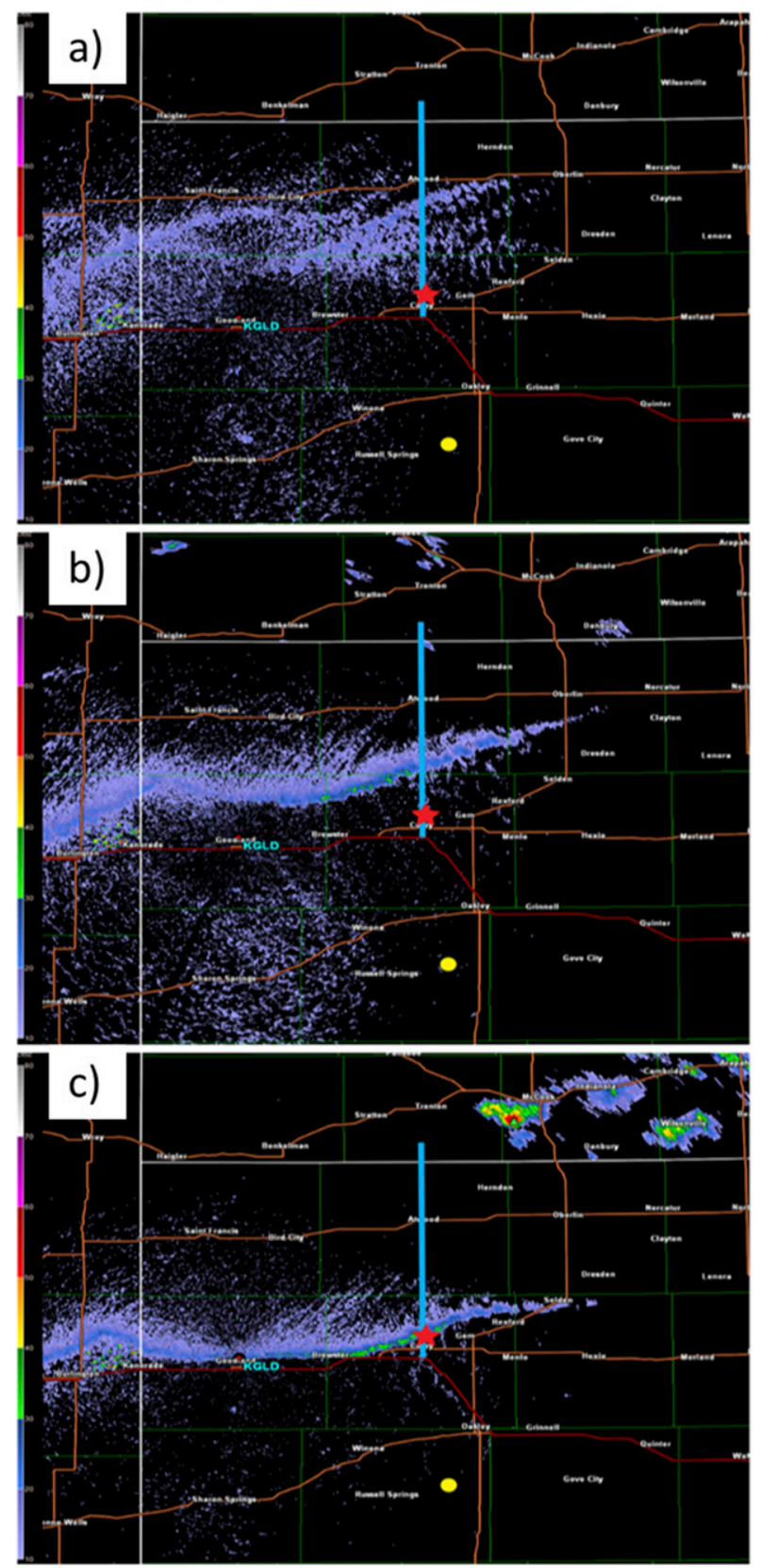

FIG. 2. Goodland, KS, WSR-88D observations of the cold front mesoscale evolution not adequately captured by the ASOS observation network at (a) 1859, (b) 2101, and (c) 2259 UTC. Also shown are the approximate locations of the surface transects (blue line), the location of KCBK (red star), and the location of the RAP sounding used in the analysis (yellow dot).

Observations collected by the CoMeT were used to modify RAP soundings to examine the possible impact of the MAHTE on SBCAPE. Initial (unmodified) RAP profiles were extracted at 2000 and 2300 UTC at a point approximately $25 \mathrm{~km}$ south of Colby, Kansas (Fig. 2). These profiles (Figs. 7a,b) were then modified using near-surface data collected by the CoMeT $\sim 10 \mathrm{~km}$ south of the cold front to represent the air mass ahead of the cold front (Figs. 7c,d) and near the location of maximum $\theta_{e}$ to represent the MAHTE (Figs. 7e,f). Low-level profiles of temperature were developed by assuming that CoMeT near-surface observations of temperature were well mixed through a $100-\mathrm{hPa}$ layer. Profiles of moisture were developed by setting the surface dewpoint temperature to that observed by the CoMeT. Based on these estimates, SBCAPE within the MAHTE may have been $3500-5000 \mathrm{~J} \mathrm{~kg}^{-1}$ higher than in the warm sector and approached values as large as $\sim 6800 \mathrm{~J} \mathrm{~kg}^{-1}$ (Fig. 7). The lifting condensation level and level of free convection were also lower in the MAHTE.

\section{3) ASOS STATION COMPARISON}

The representation of the MAHTE in surveillance meteorological data is also included for completeness. Twenty-minute data from the Colby, Kansas, ASOS (hereafter KCBK; Figs. 1, 2) over the period of our analysis are assessed. In the warm sector, $\theta_{e}$ is observed to drop from $360-364 \mathrm{~K}$ before $1700 \mathrm{UTC}$ to $358-361 \mathrm{~K}$ in the afternoon (Fig. 8). The cold front reached KCBK at approximately 2300 UTC (Fig. 8), with a corresponding drop in temperature and $10-\mathrm{K}$ increase in $\theta_{e}$ to $367 \mathrm{~K}$. This $\theta_{e}$ is roughly equivalent to the peak $\theta_{e}$ observed in the 2253 UTC transect (Fig. 3). One hour after the passage of the front, $\theta_{e}$ dropped to values below those observed in the warm air mass during the afternoon, likely due to the continued southward propagation of the MAHTE (Fig. 8). These data illustrate that MAHTEs can be identified in surveillance meteorological data. However, over the 5-h analysis period, KCBK was the only ASOS station that the MAHTE passed.

\section{Modeling component}

\section{a. Methodology}

The Advanced Research Weather Research and Forecasting (WRF-ARW) Model version 3.8 ( Skamarock et al. 2008) was utilized for the modeling component of this study. WRF was initialized using analysis fields from the 4-km North American Mesoscale Forecast System (NAM). The outer domain of this study was $950 \mathrm{~km} \times 750 \mathrm{~km}$ and had a grid spacing of $1 \mathrm{~km}$, with an inner domain of dimensions $150 \mathrm{~km} \times 150 \mathrm{~km}$ nested down to $333-\mathrm{m}$ grid spacing (Fig. 9). Ninety vertical levels were selected, preferentially stacked within the boundary layer with approximately 38 levels below $2 \mathrm{~km}$ and the lowest level at $25 \mathrm{~m}$ AGL. The high resolution was chosen to ensure that processes occurring within the 


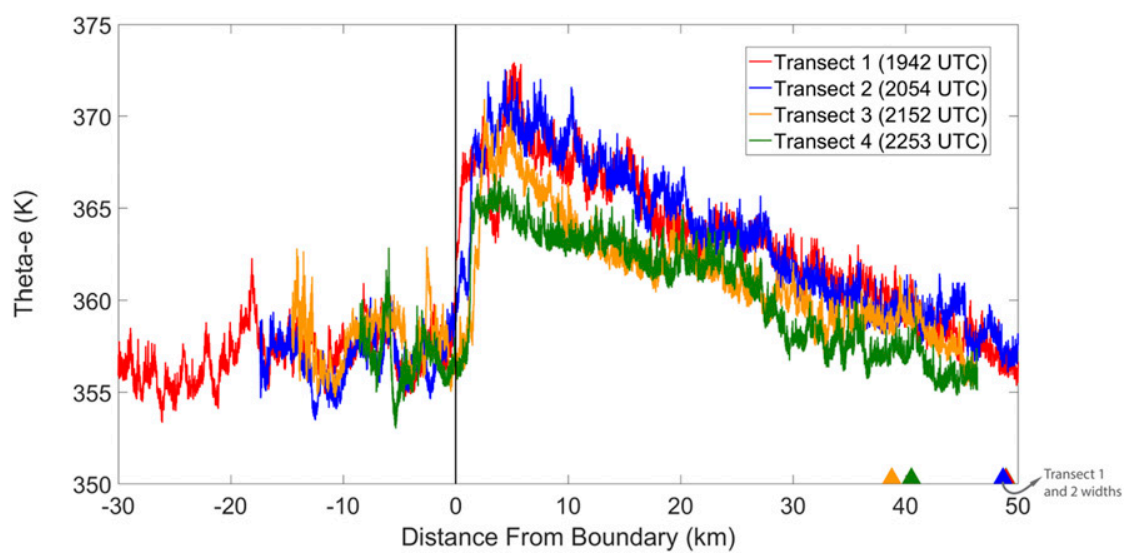

FIG. 3. Values of $\theta_{e}$ taken during each transect: 1 (1942 UTC, red), 2 (2054 UTC, blue), 3 (2152 UTC, orange), and 4 (2253 UTC, green). Observations are transformed into a boundary relative frame of reference, where positive distances represent the cool side of the boundary, and negative distances represent the warm side of the boundary. Colored triangles denote the width of the MAHTE observed during each transect.

MAHTE would be well resolved. This inner domain was centered near where CoMeT data were collected. The model was initialized at 1400 UTC 20 June 2016, approximately $2-3 \mathrm{~h}$ before the MAHTE formed, to allow adequate spinup time and for analysis of the conditions leading up to MAHTE formation. The model was run without nudging until 0200 UTC 21 June 2016.

Simulations used the Rapid Radiative Transfer Model (RRTM) radiation longwave radiation parameterization (Mlawer et al. 1997) with the Dudhia shortwave radiation parameterization (Dudhia 1989). The RRTM longwave radiation scheme was selected because of its accuracy in accordance with line-by-line calculations of radiative transfer (Mlawer et al. 1997). The Morrison microphysics parameterization (Morrison et al. 2009) was selected for the microphysical scheme. This is a two-moment microphysics scheme that parameterizes five different water phases and is ideally suited for accurate representation of deep convective processes. Although deep convection is not simulated in this work, storm-generated MAHTEs will be the focus of future work, and Morrison microphysics are therefore included for consistency with this subsequent research. The Mellor-Yamada-Nakanishi-Niino (MYNN) planetary boundary layer (PBL) and surface physics schemes were selected because of their demonstrated ability to predict PBL height, as well as afternoon temperature and moisture, compared to other schemes (Coniglio et al. 2013). Finally, the unified Noah land surface model (Tewari et al. 2004) was selected as the land surface scheme in accordance with prior work (e.g., Coniglio et al. 2013; Burghardt et al. 2014). The unified Noah land

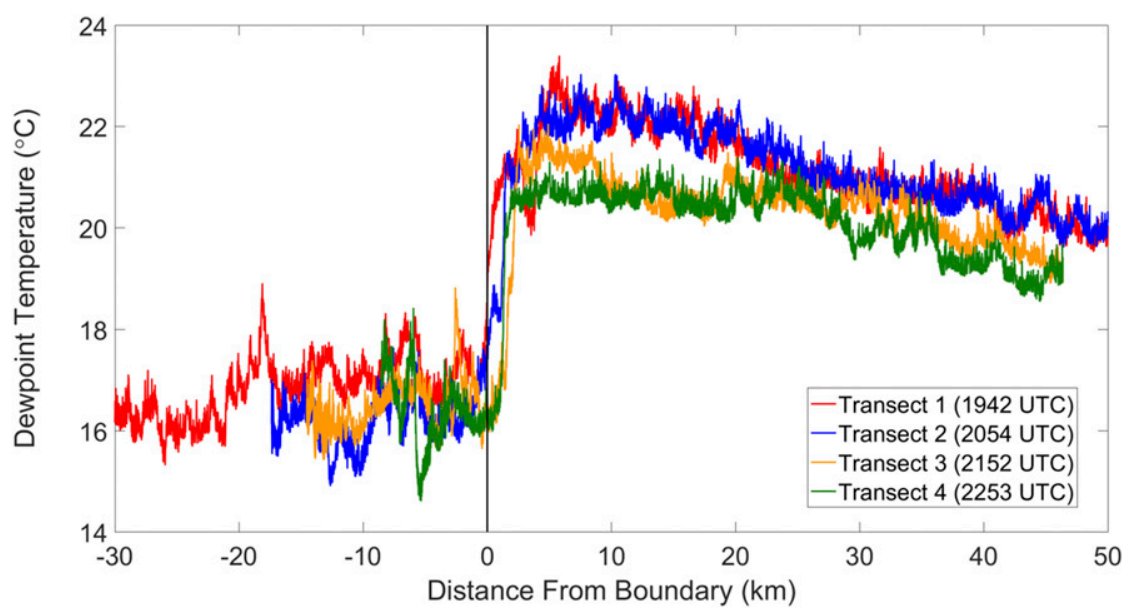

FIG. 4. As in Fig. 3, but for observed dewpoint temperature. 


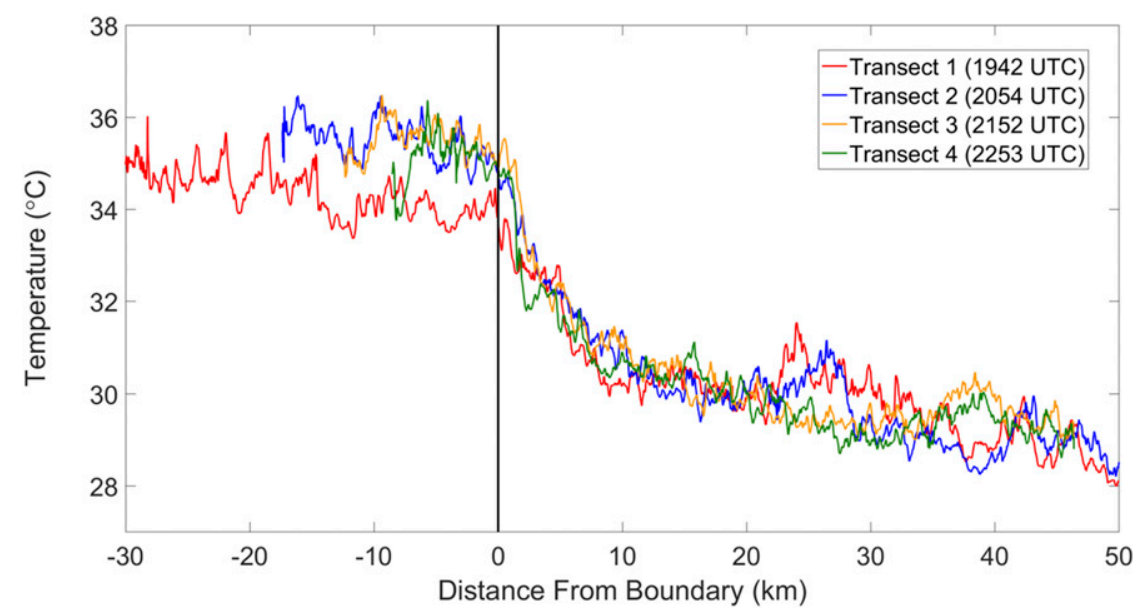

FIG. 5. As in Fig. 3, but for observed temperature.

surface model has four soil layers and calculates soil moisture and temperature, as well as surface energy fluxes. It uses one vegetation layer and assigns one vegetation type per grid cell when making temperature and flux calculations (Chen et al. 2012). Other more complex surface models are available, such as the Community Land Model (CLM4), which utilizes more soil layers, more vegetation types, and calculates temperature and surface energy fluxes for eight subgrids (Okalebo et al. 2016). However, due to the high resolution of our simulations, it is assumed that the Noah land surface will be sufficient for representing surface energy fluxes in this study. Future work aims to evaluate the sensitivity of MAHTE simulation/prediction to land surface models.

To examine the time evolution of surface variables during MAHTE formation, averages were calculated over two $15 \mathrm{~km} \times 15 \mathrm{~km}$ areas (Figs. 10-12): 1) the region within the MAHTE exhibiting the largest increase in $\theta_{e}$ during MAHTE formation and 2) a region representative of the air mass south of the boundary. These locations remained fixed in space throughout the analysis period.

\section{b. Results}

Although absent at initialization, a MAHTE develops in the simulation as early as 1600 UTC (Fig. 10b) and, by 2200 UTC (Fig. 10e), is characterized by an increase in $\theta_{e}$ of approximately $15 \mathrm{~K}$ across the front, similar to observations (cf. Fig. 3). The maximum $\theta_{e}$ that manifests within the MAHTE is approximately $372 \mathrm{~K}$ immediately north of the front-a magnitude and front-relative position that is similar to observations. Moreover, simulated dewpoint temperatures reach a maximum value of approximately $22^{\circ} \mathrm{C}$ within the MAHTE, which is only $1^{\circ} \mathrm{C}$ lower than the maximum observed dewpoint

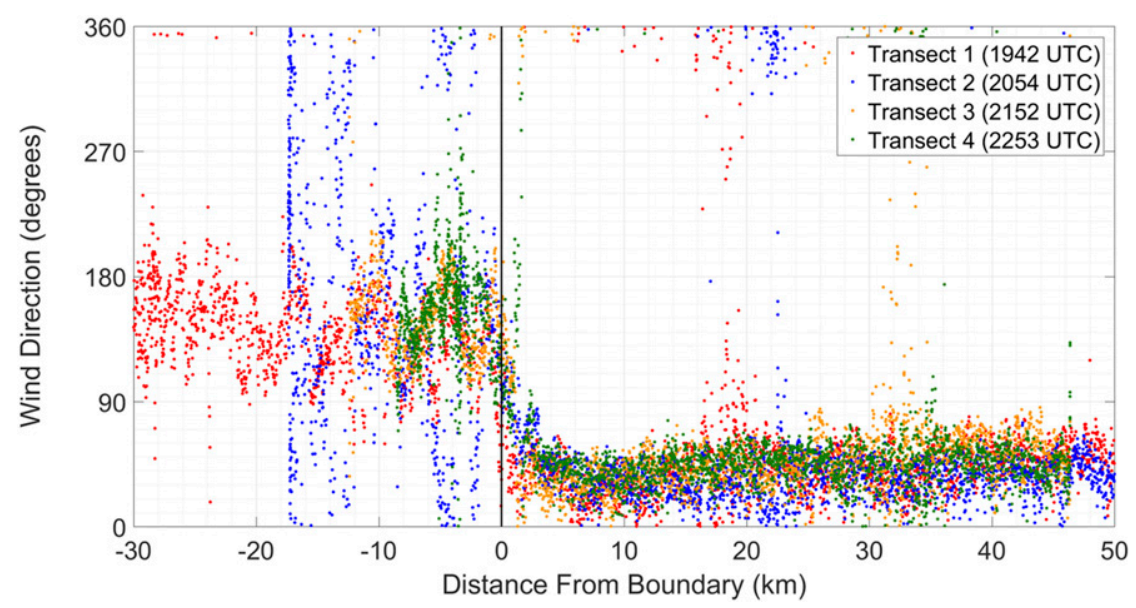

FIG. 6. As in Fig. 3, but for observed wind direction. 
a)

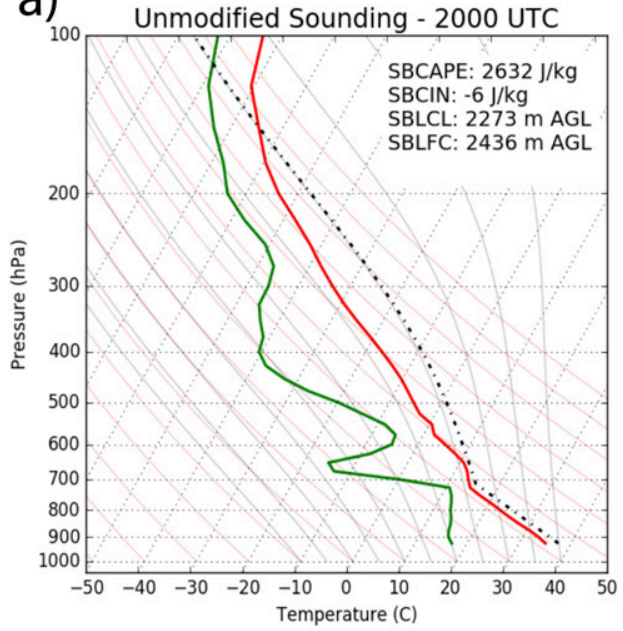

c)

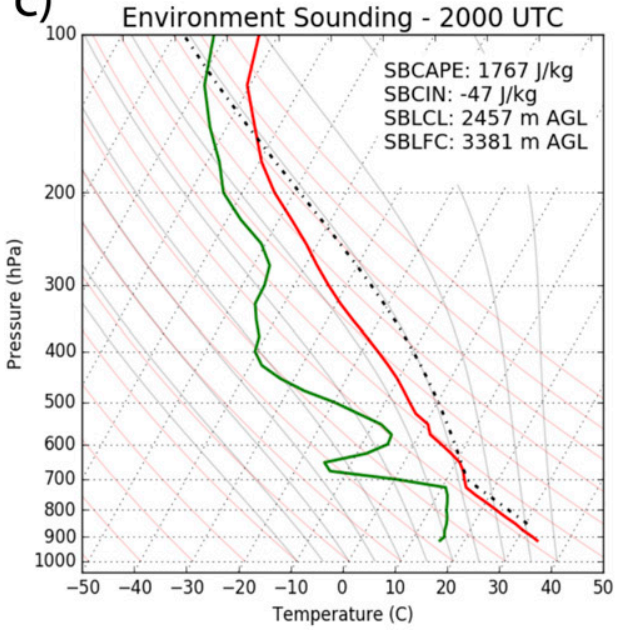

e)

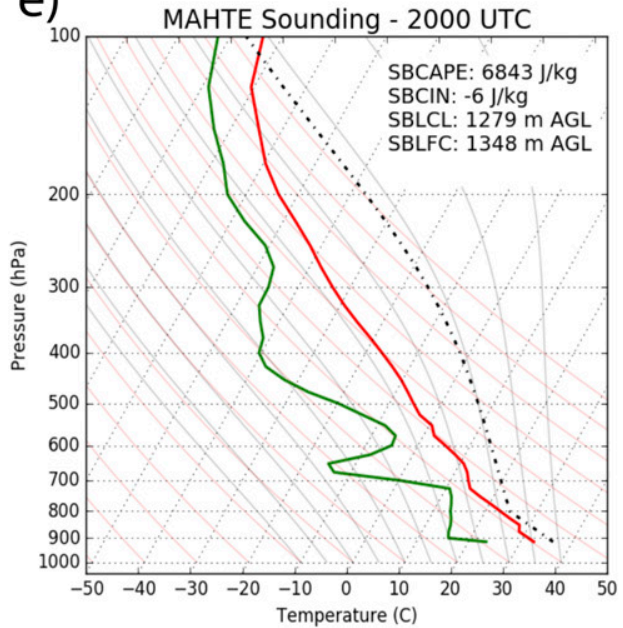

b)

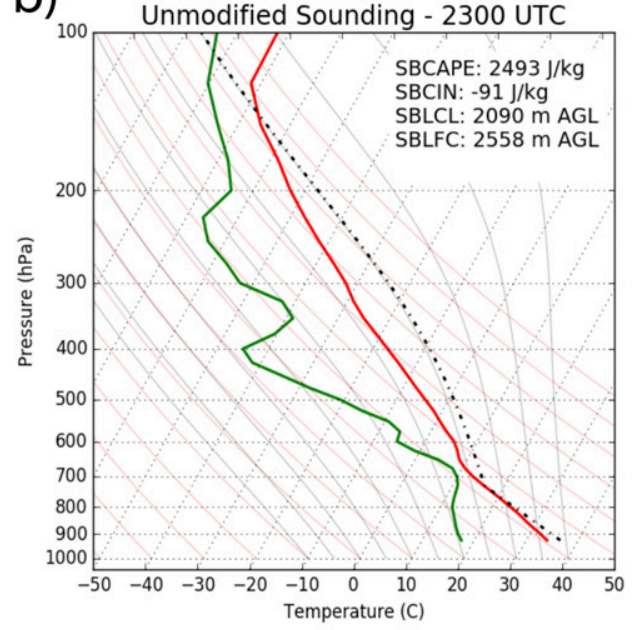

d)

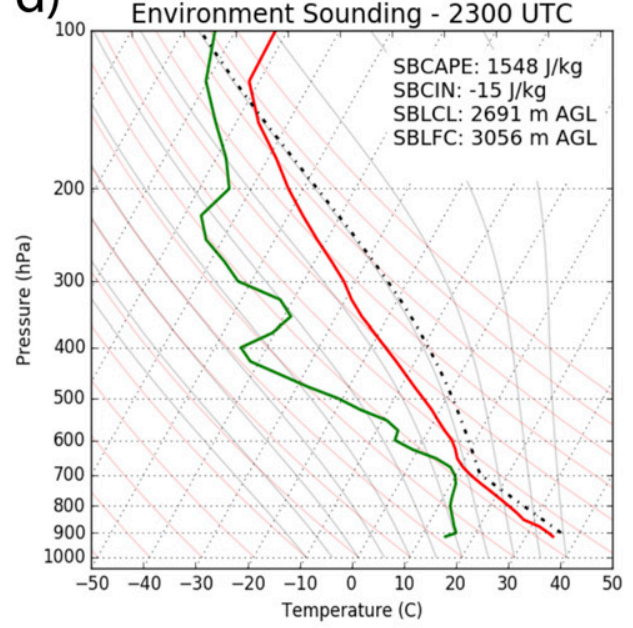

f)

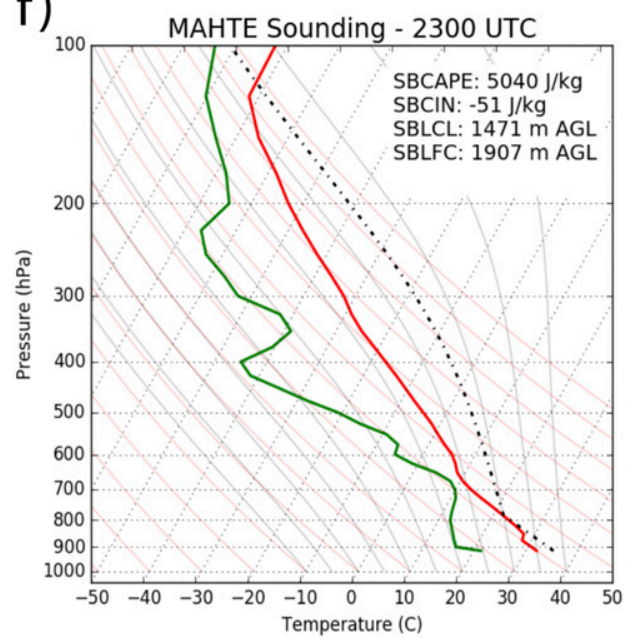

FIG. 7. (a),(b) Unmodified RAP soundings; (c),(d) RAP soundings modified with surface observations in the warm environment; and (e),(f) RAP soundings modified with surface observations in the MAHTE for (left) 2000 and right 2300 UTC. 


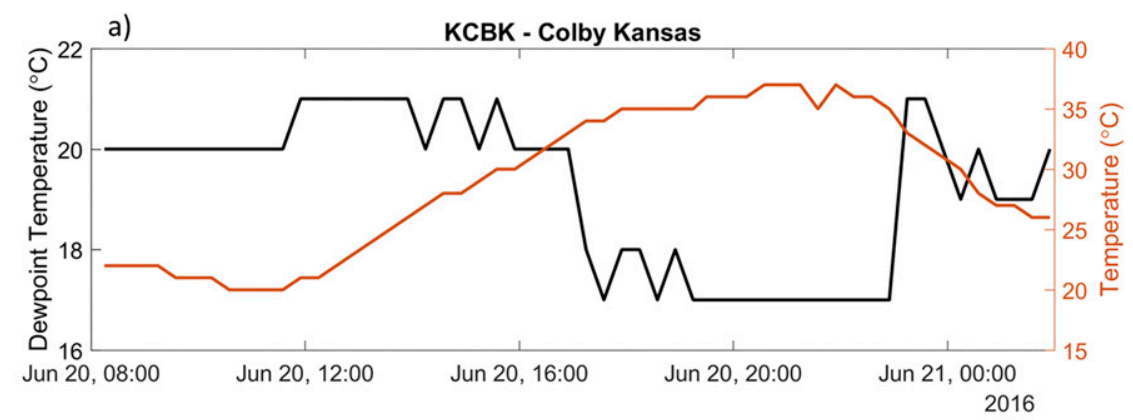

b)

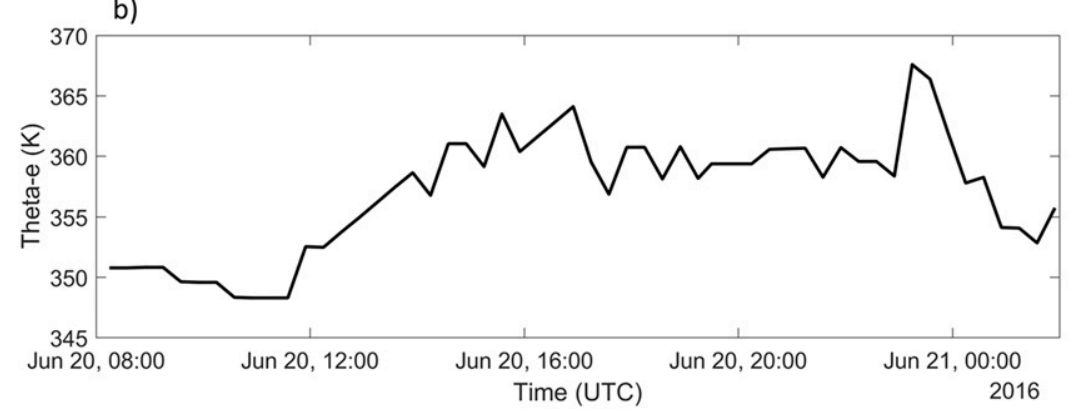

FIG. 8. (a) Surface observations of dewpoint temperature $\left({ }^{\circ} \mathrm{C}\right.$; black) and temperature $\left({ }^{\circ} \mathrm{C}\right.$; red) and (b) surface observations of $\theta_{e}$ from KCBK from 0800 UTC 20 Jun to 0200 UTC 21 Jun 2016. The MAHTE passed over KCBK at approximately 2300 UTC.

temperature, and the maximum simulated MAHTE dewpoint temperature is $\sim 6^{\circ} \mathrm{C}$ higher than the warm sector, which is also similar to observations. The correspondence between simulation and observations affords the liberty of assuming that the simulated processes responsible for MAHTE formation closely resemble the observed processes.

At 1400 UTC (simulation initialization), the cold front, manifested principally in the wind field, is located near latitude $40^{\circ} \mathrm{N}$ (Fig. 11a). Simulated $2-\mathrm{m} \theta_{e}$ is highest at this time to the south of the front (Fig. 10a). By 1600 UTC, temperatures have increased more rapidly south of the front, compared to north of the front (Fig. 11b), and dewpoint temperatures south of the front have decreased (Fig. 12b). Driven by the decrease in moisture south of the front, $\theta_{e}$ is slightly higher north of the front (Fig. 10b). Cross sections illustrate convective boundary layer (CBL) development is underway at 1600 UTC (Fig. 13b). By 1800 UTC, the CBL has deepened to $\sim 2000 \mathrm{~m}$ AGL south of the front (Fig. 13c) and is associated with a decrease in $\theta_{e}$ (Figs. 10c, 13c). In addition to Fig. 13, the evolution of the cross-sections of $\theta_{e}$ is illustrated at a higher temporal resolution (see animations in online supplemental material). From 1400 to 1800 UTC, $\theta_{e}$ south of the cold front decreases by as much as $8-12 \mathrm{~K}$, leading to a $\theta_{e}$ that is $\sim 10 \mathrm{~K}$ higher north of the front by 1800 UTC (Fig. 10c). This reduction of $\theta_{e}$ in the warm sector is due to decreases in low-level moisture: average dewpoint temperatures across the southern subdomain decrease approximately $5^{\circ} \mathrm{C}$ between 1600 and 1800 UTC (Fig. 12a). Area-averaged dewpoint temperatures and $\theta_{e}$ capture this transition (Figs. 14b,c). Furthermore, area-averaged temperature over this time period exhibits increases on both sides of the front but more significant increases to the south (Fig. 14a). During the transition to a CBL (1600-1800 UTC), these rapid

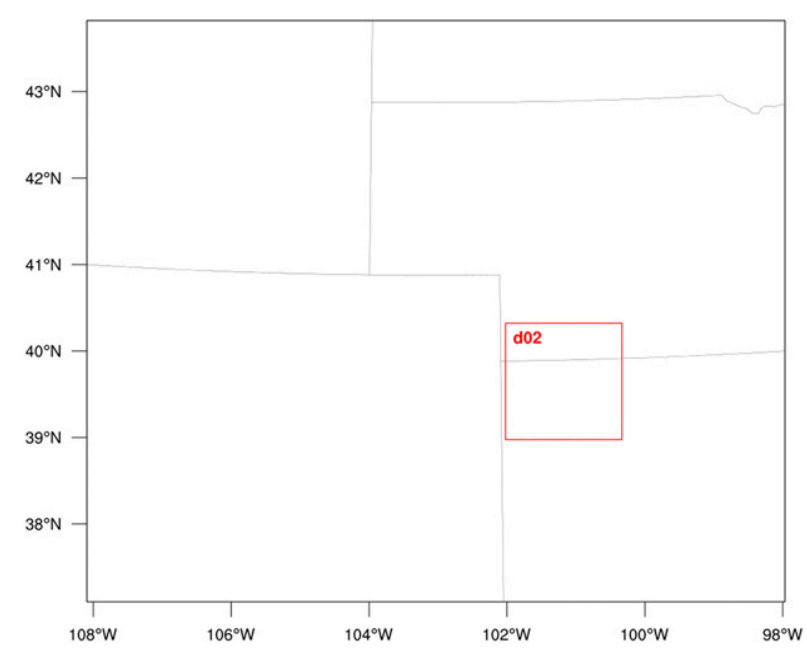

FIG. 9. WRF domain configuration used for simulations. Domain 2, shown by the red square, was used for all analyses. 


\section{$2 \mathrm{~m}$ Theta-e (K)}

a)

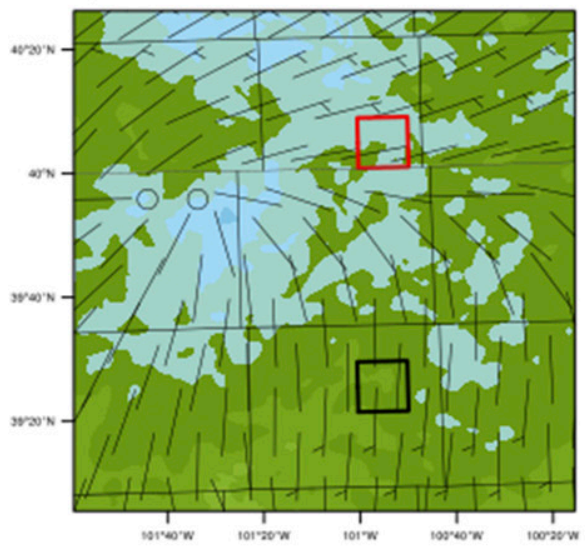

c)

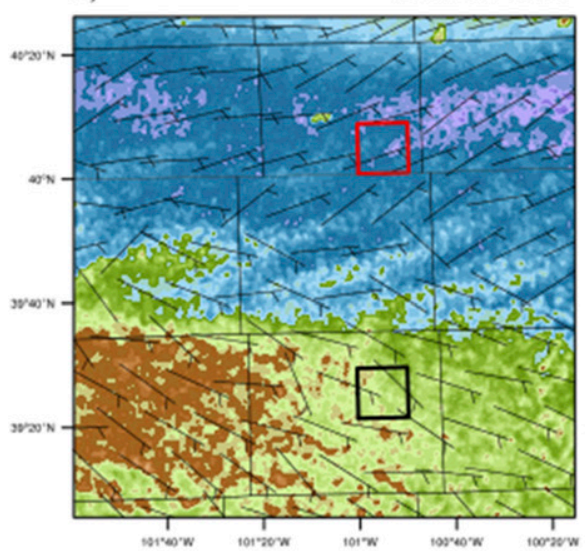

e)

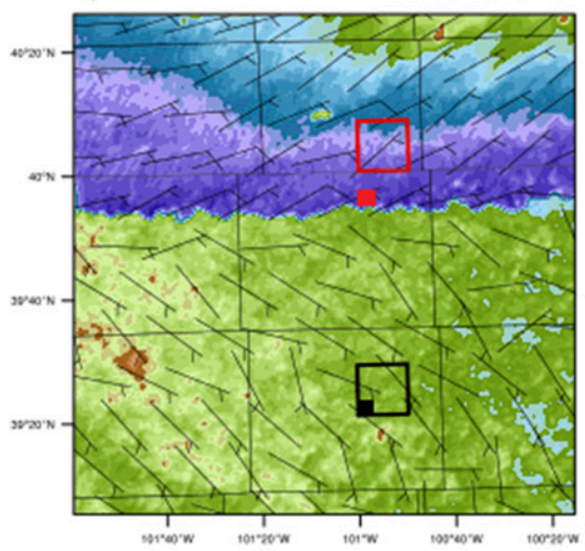

b) 16:00:00 UTC

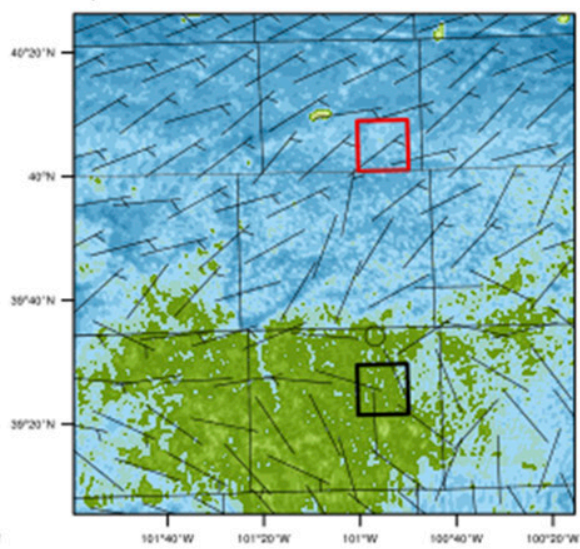

d)

20:00:00 UTC
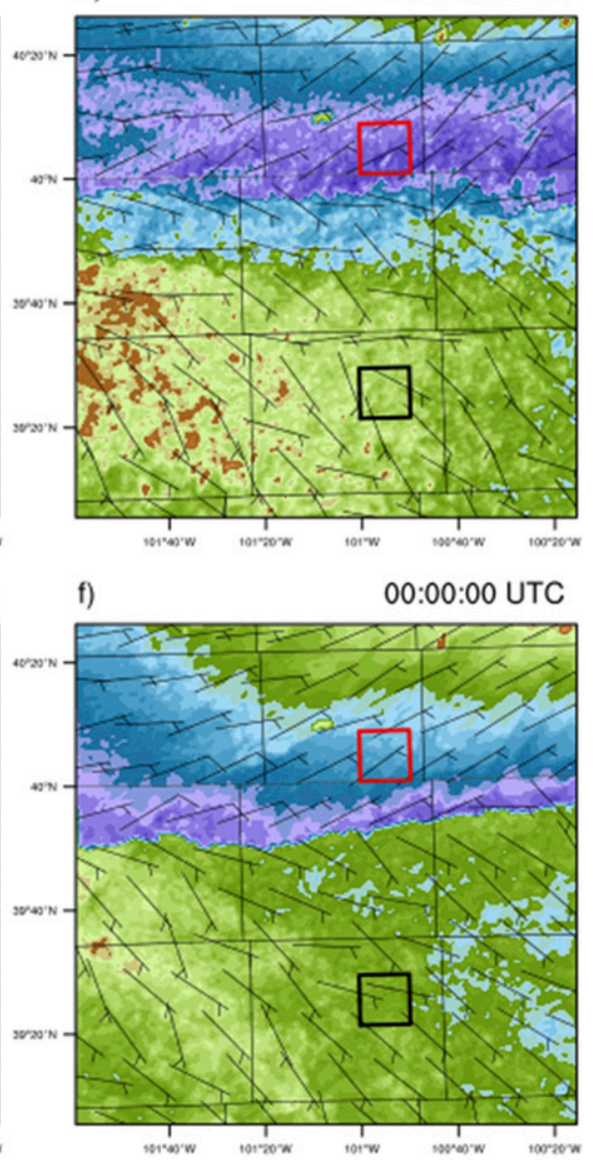

$\begin{array}{llllllll}340 & 344 & 348 & 352 & 356 & 360 & 364 & 368\end{array}$

FIG. 10. Simulated 2-m $\theta_{e}$ (color shading, $\mathrm{K}$ ) and 10-m wind (barbs, $\mathrm{m} \mathrm{s}^{-1}$ ) at (a) initialization of the model; (b),(c) prior to the development of the MAHTE; (d) during MAHTE formation; (e) at peak intensity of the MAHTE; and (f) the beginning of the dissipation of the MAHTE. Colored squares indicate the areas used for calculating averages in the MAHTE (red) and the warm environment (black).The small solid red square is the location of the average MAHTE sounding, and the solid black one is the location of the average environment sounding. 


\section{2 m Temperature $(C)$}

a)

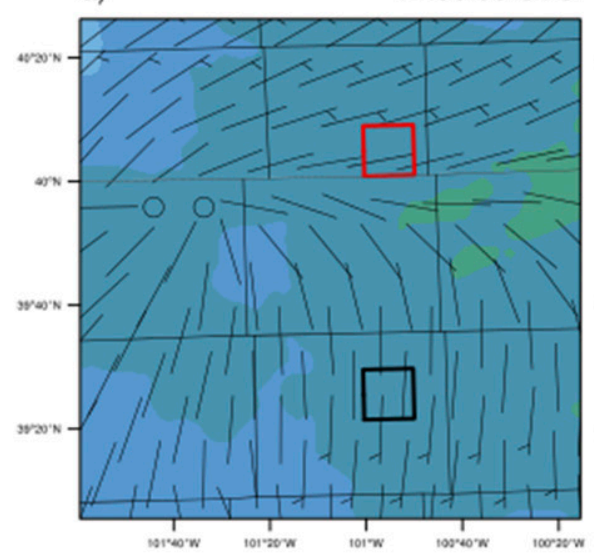

c)

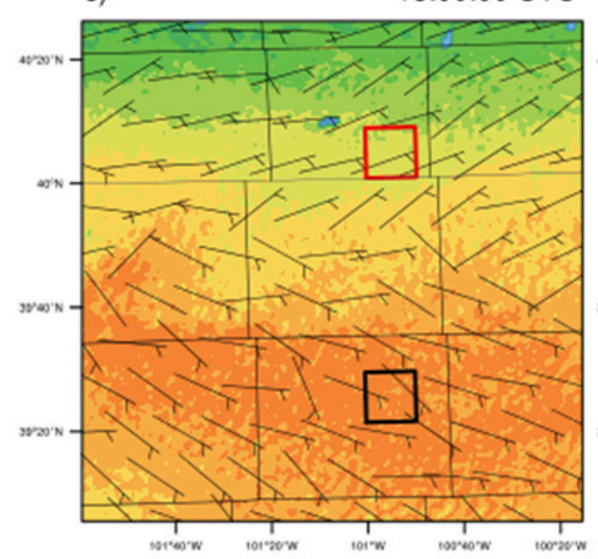

e)

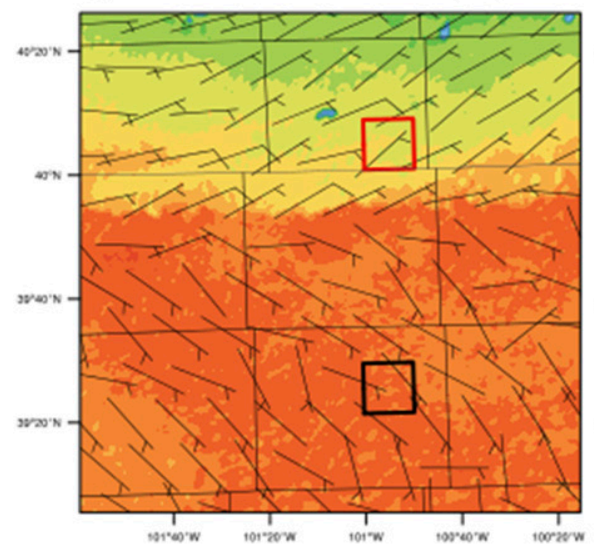

b) 16:00:00 UTC
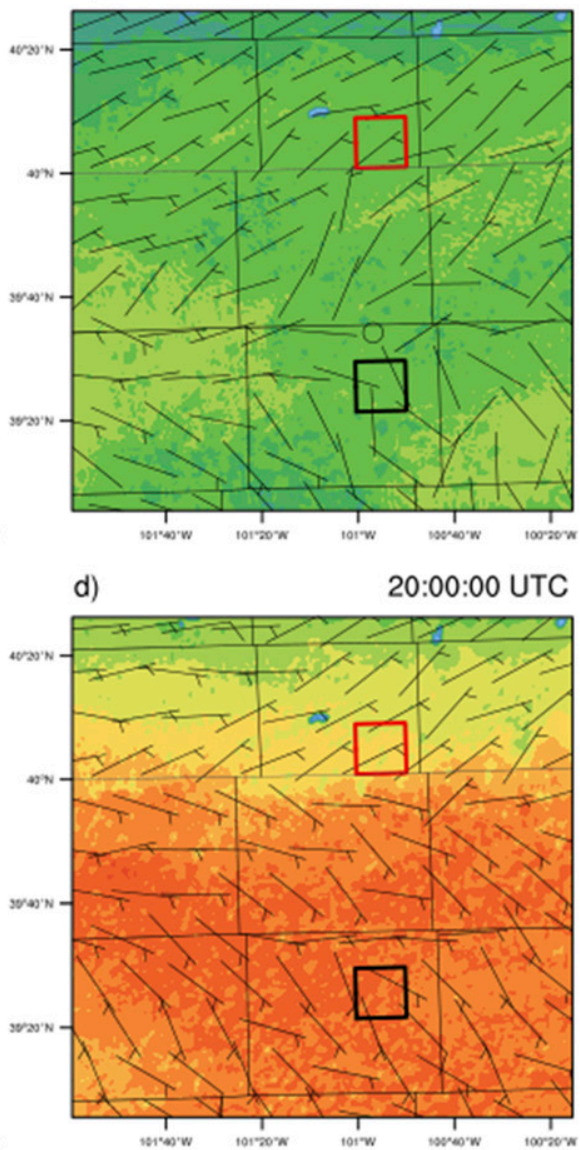

f)

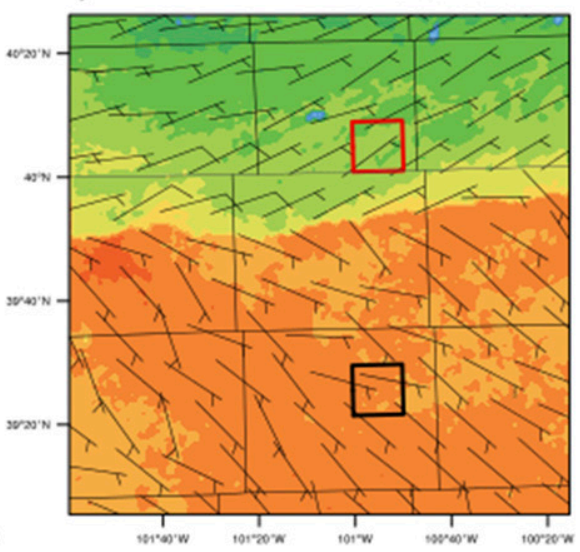

$\begin{array}{llllllll}24 & 26 & 28 & 30 & 32 & 34 & 36 & 38\end{array}$

Fig. 11. As in Fig. 10, but for simulated 2-m temperature $\left({ }^{\circ} \mathrm{C}\right)$ and $10-\mathrm{m}$ winds $\left(\mathrm{m} \mathrm{s}^{-1}\right)$. 


\section{2 m Dewpoint Temperature $(C)$}

a)

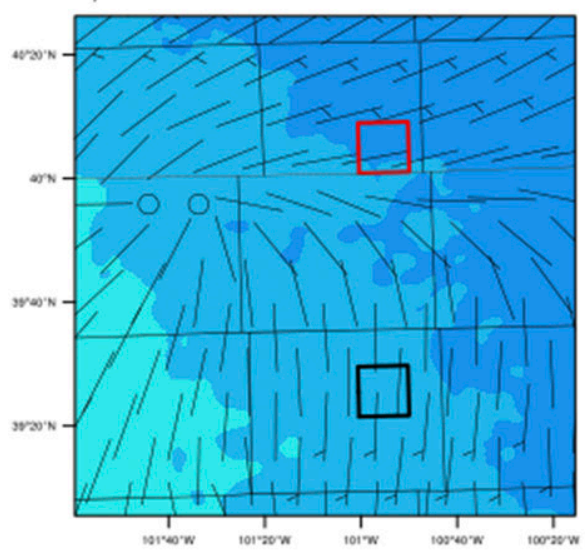

c)

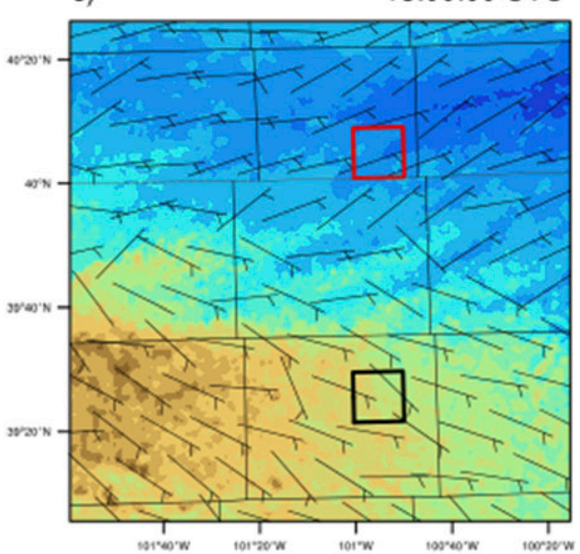

e)

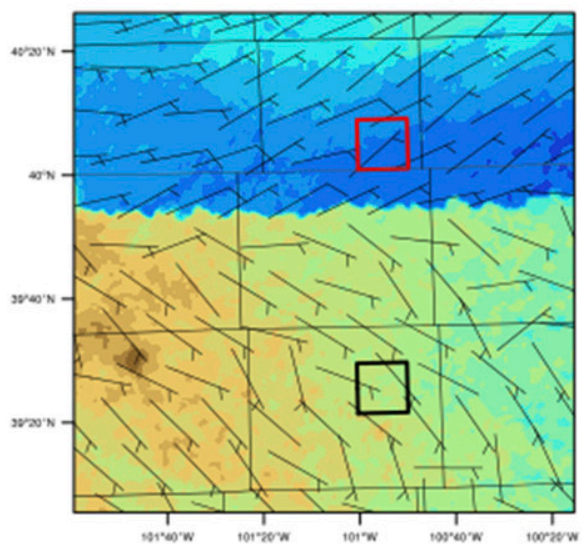

b)

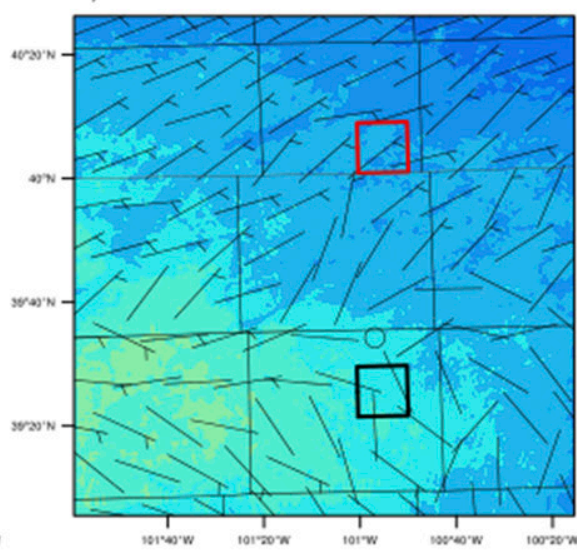

d)

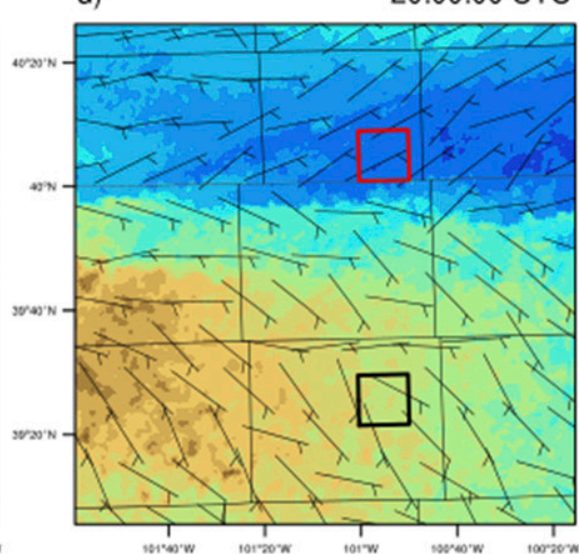

00:00:00 UTC

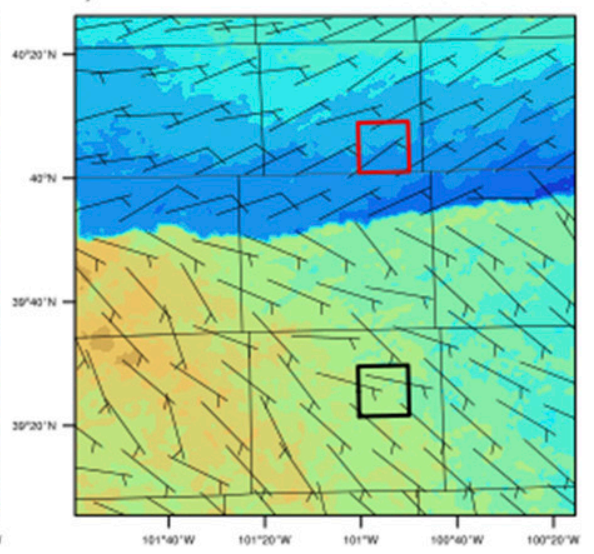

$\begin{array}{lllllllll}10 & 12 & 14 & 16 & 18 & 20 & 22 & 24 & 26\end{array}$

FIG. 12. As in Fig. 10, but for simulated 2-m dewpoint temperature $\left({ }^{\circ} \mathrm{C}\right)$ and $10-\mathrm{m}$ winds $\left(\mathrm{m} \mathrm{s}^{-1}\right)$. 


\section{Vertical Cross Section of Theta-e}

a) 14:00:00 UTC

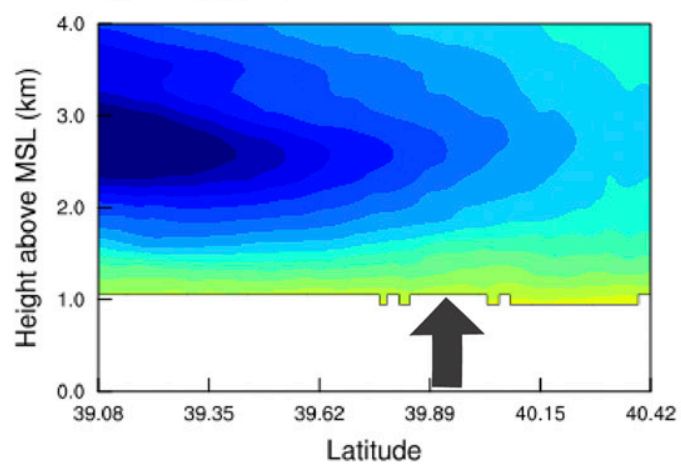

c) $18: 00: 00$ UTC

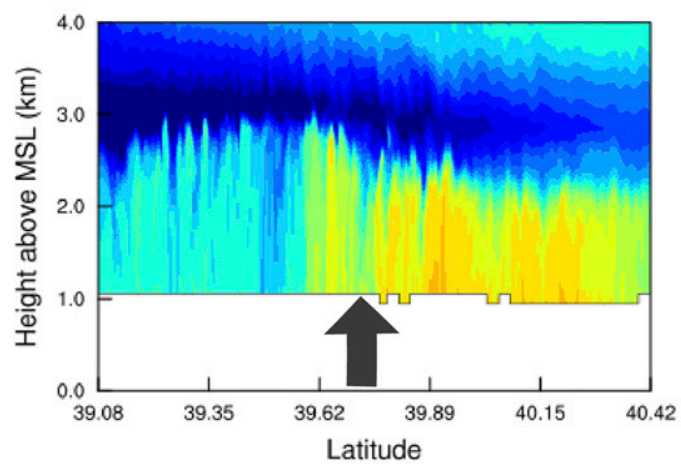

e) 22:00:00 UTC

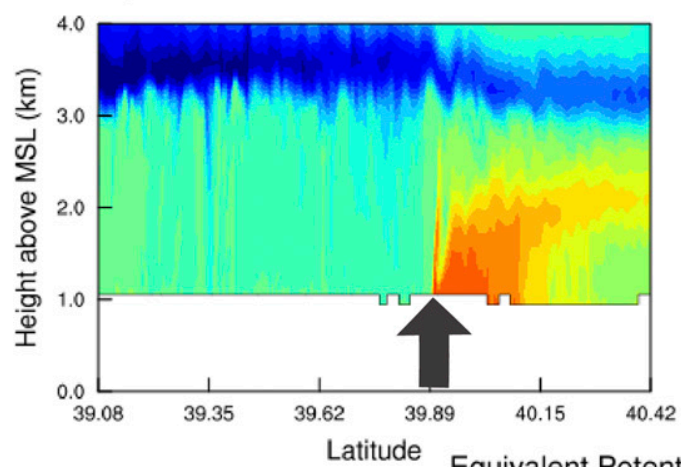

b) 16:00:00 UTC

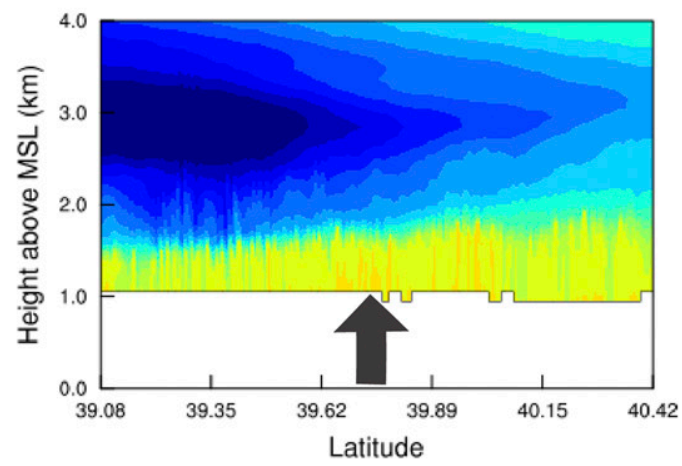

d) 20:00:00 UTC

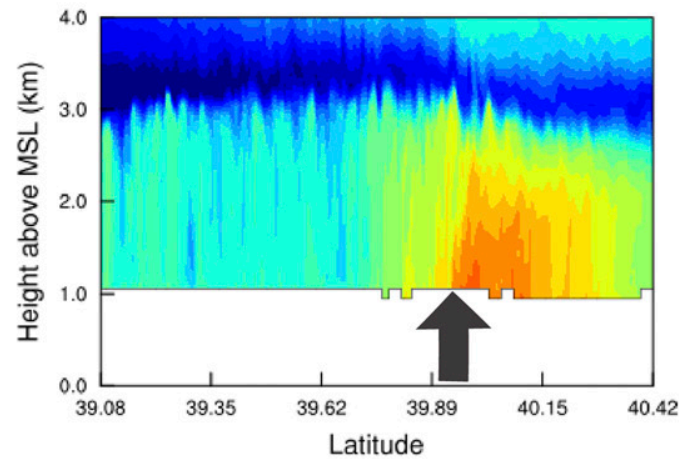

f) 00:00:00 UTC

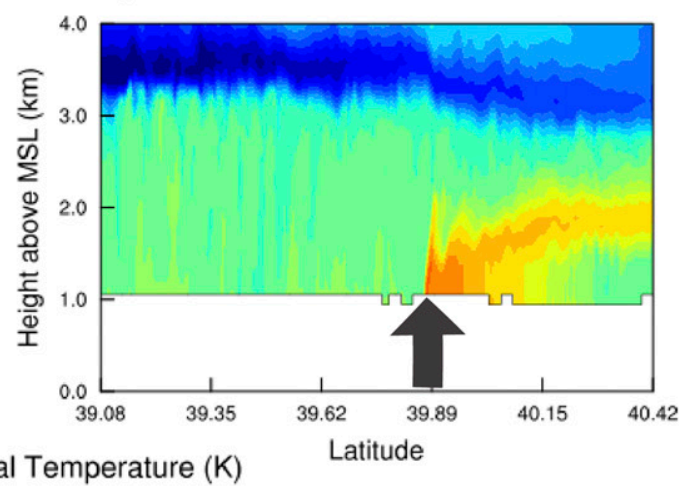

$\begin{array}{lllllllllll}330 & 334 & 338 & 342 & 346 & 350 & 354 & 358 & 362 & 366 & 370\end{array}$

FIG. 13. South-north vertical cross section of simulated $\theta_{e}$ (K) from (a)-(f) 1800 to 0000 UTC. The approximate location of the cold front is indicated by the black arrow.

changes in the simulated 2-m fields of $\theta_{e}$, dewpoint temperature, and temperature to the south of the boundary are in close agreement with observations from KCBK (cf. Fig. 8). This lends further credence to the assumption that simulated processes responsible for MAHTE formation closely resemble the observed processes.
Over the period from 1800 to 2000 UTC, $\theta_{e}$ continues to increase north of the front (Fig. 10d), with peak values reaching $369 \mathrm{~K}$. As a consequence of the north-south temperature gradient (Figs. 11c,d), the $\theta_{e}$ gradient reverses direction $3-5 \mathrm{~km}$ north of the cold front (Figs. 10c,d), yielding $\theta_{e}$ along the northern extent of the analysis domain that is nearly identical to the warm sector. 

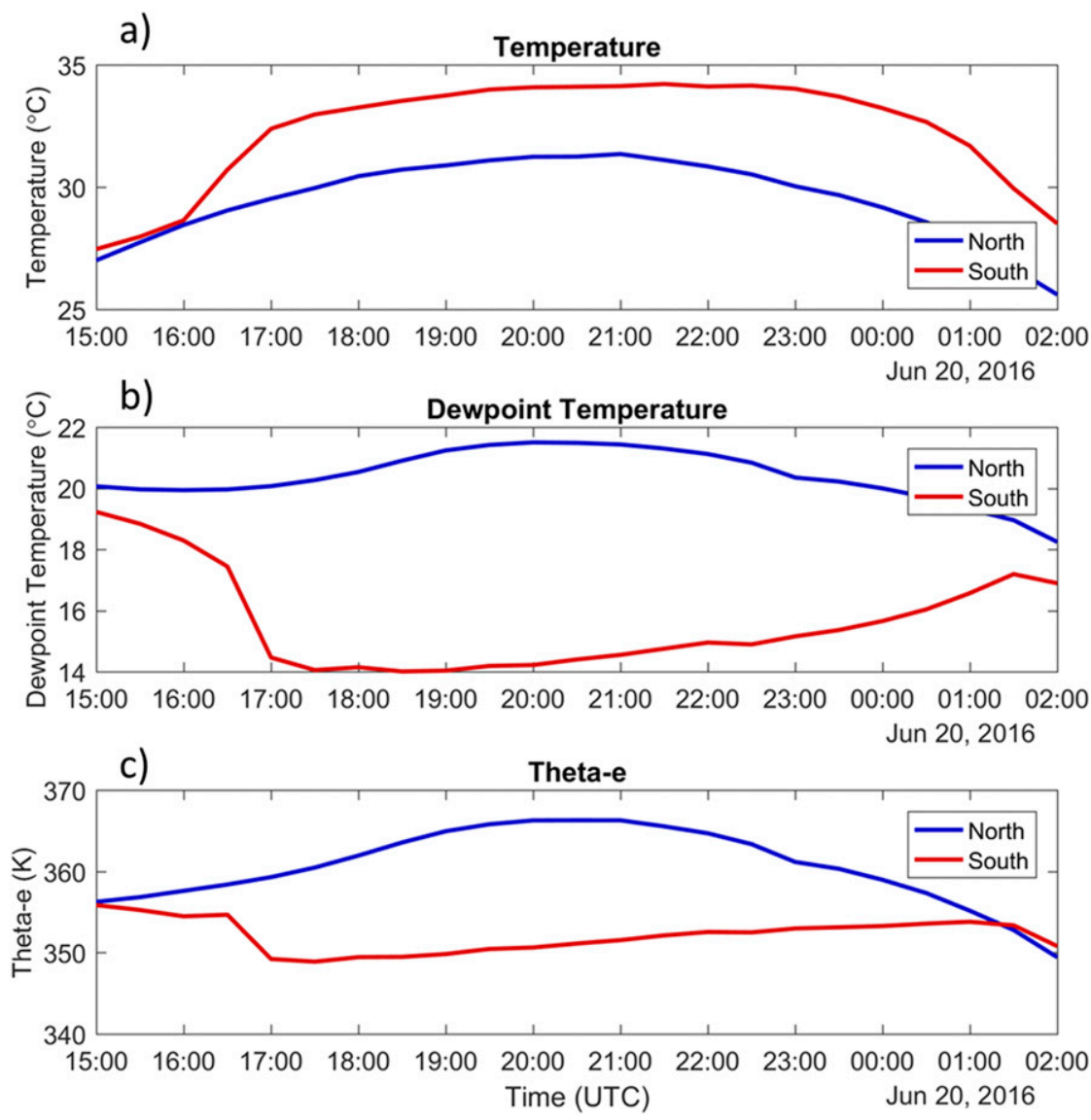

FIG. 14. Area averages of 2-m (a) temperature $\left({ }^{\circ} \mathrm{C}\right),(\mathrm{b})$ dewpoint temperature $\left({ }^{\circ} \mathrm{C}\right)$, and $(\mathrm{c}) \theta_{e}$

(K) for north (blue) and south (red) of the front.

This $\sim 35-\mathrm{km}$-wide zone of high $\theta_{e}$ north of the front is the MAHTE.

By 2200 UTC, domain-maximum $\theta_{e}$ has increased to $\sim 372 \mathrm{~K}$ and is located directly along the cold side of the cold front (Fig. 10e). This value and front-relative position of maximum $\theta_{e}$ is nearly identical to observations collected by the CoMeT (cf. Fig. 3). Simulated dewpoint temperatures reach a maximum value around 2200 UTC of approximately $22^{\circ} \mathrm{C}$ within the MAHTE, which is $1^{\circ} \mathrm{C}$ lower than the maximum observed dewpoint temperature. Moreover, the simulated MAHTE dewpoint temperature is $\sim 6^{\circ} \mathrm{C}$ higher than the warm sector, similar to observations. Beyond 2200 UTC, peak $\theta_{e}$ within the MAHTE decreases, and the overall width of the MAHTE contracts (Fig. 10f). The decrease in $\theta_{e}$ is due to a slight reduction in surface dewpoint temperature to the north of the front (Fig. 12f), as well as a reduction in temperature across the entire domain (Fig. 11f) due to decreased insolation.

Averaged vertical profiles of thermodynamic state variables within the warm sector and the MAHTE are evaluated using data from a $3 \mathrm{~km} \times 3 \mathrm{~km}$ area in the warm sector, roughly corresponding to the position of the RAP soundings used in section 3 , and from a $3 \mathrm{~km} \times$ $3 \mathrm{~km}$ area within the MAHTE at the location of maximum $\theta_{e}$ cantered about the same longitude of the CoMeT transects (refer to Fig. 10e for these averaged areas at 2200 UTC). Average soundings were examined to mitigate potential impacts that thermals could have on a sounding taken from a single point. Model soundings at 2200 UTC (Fig. 15) reflect a well-mixed boundary layer up to approximately $725 \mathrm{hPa}$ in the warm sector. Within the MAHTE, a shallow statically stable layer is in place near $850 \mathrm{hPa}$ with approximately well-mixed conditions below and above it. Temperature and moisture above the stable layer within the MAHTE are nearly identical to the well-mixed conditions within the warm sector. Resembling an elevated mixed layer, this warm-sector air mass just above the MAHTE likely suppresses mixing between the MAHTE and the more conventional elevated mixed layer located above $700 \mathrm{hPa}$. This suppression of vertical mixing would allow moisture content and $\theta_{e}$ within the MAHTE to remain higher into the afternoon. 


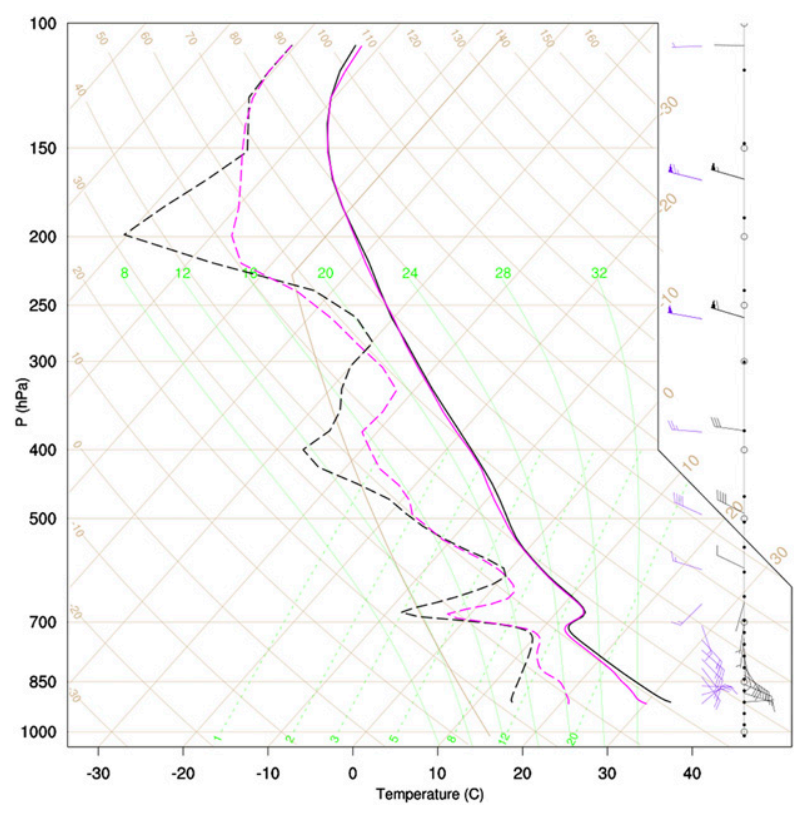

FIG. 15. Soundings taken in the warm environment (black) and in the MAHTE (magenta). Solid lines indicate temperature, and dashed lines indicate dewpoint temperature.

Soundings derived from these simulations are generally consistent with the modified RAP soundings using near-surface observations. These modified soundings, discussed previously, showed that SBCAPE was likely significantly higher within the MAHTE, compared to the warm environment. Simulated SBCAPE at 2200 UTC (the time of the highest $\theta_{e}$ ) also reflects this (Fig. 16a). SBCAPE within the MAHTE approaches $4000 \mathrm{~J} \mathrm{~kg}^{-1}$ directly on the cold side of the front, with SBCAPE below $1000 \mathrm{~J} \mathrm{~kg}^{-1}$ in the warm air mass. Thus, similar to differences observed using the modified RAP soundings (section 3), the MAHTE was characterized by CAPE nearly $3000 \mathrm{~J} \mathrm{~kg}^{-1}$ larger than in the warm sector. Within the MAHTE, surface-based convective inhibition (SBCIN) decreased throughout the morning, reaching values between 0 and $-25 \mathrm{~J} \mathrm{~kg}^{-1}$ by 2200 UTC (Fig. 16b) -values considerably smaller in magnitude than in the warm sector.

\section{Discussion of processes leading to MAHTE formation}

As reviewed in section 2, Eulerian changes to $\theta_{e}$ can be a consequence of insolation, phase transitions of water, diffusion of water vapor into the system, frictional dissipation, molecular diffusion, surface fluxes of energy, surface fluxes of moisture, and advection of variables on which $\theta_{e}$ depends (e.g., moisture and temperature). Since MAHTE formation should manifest as a cross-boundary gradient in $\theta_{e}$ tendency, the absolute magnitude of the tendency is less important than the tendency differences between the warm and cold sides of the attendant airmass boundary. Thus, it is reasonable to assume that of these forcings of $\theta_{e}$ tendency, only insolation, surface fluxes, and advection are likely to differ substantially across an airmass boundary. However, sensible heat fluxes alone are unlikely to produce higher $\theta_{e}$ on the cool side of a front, and absent cross-boundary differences in insolation (neither the observations nor the simulation are characterized by significant cloud cover or land-use differences across the boundary) are not likely a direct cause of MAHTE formation. Therefore, subsequent analysis focuses on moisture flux and $\theta_{e}$ advection as the most likely processes responsible for MAHTE formation in this simulation.

Increased surface moisture flux within the colder air mass attributable to stronger surface winds could increase atmospheric moisture (Yokoi et al. 2014). However, throughout the development stages of the MAHTE, surface fluxes of moisture are nearly identical across the front and become slightly higher south of the front (Fig. 17a). Thus, this forcing alone cannot be responsible for maintaining moisture within the MAHTE relative to the warm sector.

Cross-frontal differences in horizontal $\theta_{e}$ advection are small during the early stages of MAHTE formation (Fig. 17b), with both areas having near-zero horizontal $\theta_{e}$ advection. Horizontal $\theta_{e}$ advection becomes more negative south of the front around 1700 UTC, decreasing to -5 to $10 \times 10^{-4} \mathrm{~K} \mathrm{~s}^{-1}\left(1.8-3.6 \mathrm{~K} \mathrm{~h}^{-1}\right)$, but increases to near zero by 1730 UTC and remains small throughout the remainder of the simulation. Horizontal advection becomes negative north of the front after 2000 UTC as the southward-directed $\theta_{e}$ gradient to the north of the MAHTE moves into the area used for averaging.

Given the negative vertical gradient of $\theta_{e}$ in place (Fig. 13), typical of a conditionally unstable atmosphere, it stands to reason that stronger downward motion in the warm sector, compared to the cold side of the front, could create larger negative vertical advection to the south. Cross sections reveal that deeper and stronger mixing exists south of the front, particularly after 1600 UTC (Figs. 13, 18). This evolution of simulated differential vertical mixing across the boundary is further illustrated at a higher temporal resolution in the supplemental gifs of vertical cross-sections of vertical velocity. The associated downward motion acting on the background negative $\theta_{e}$ gradient, which is more negative south of the front, should result in a differential $\theta_{e}$ tendency across the front. To quantify the impacts of differential vertical advection on the development of the 
a)

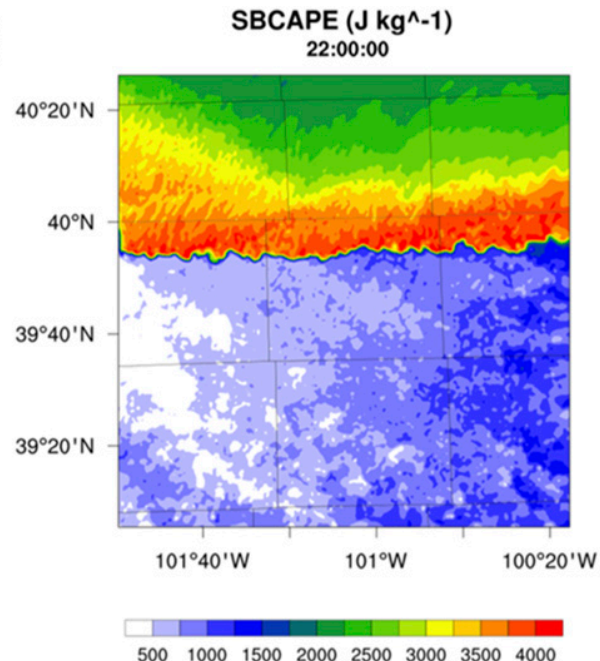

b)

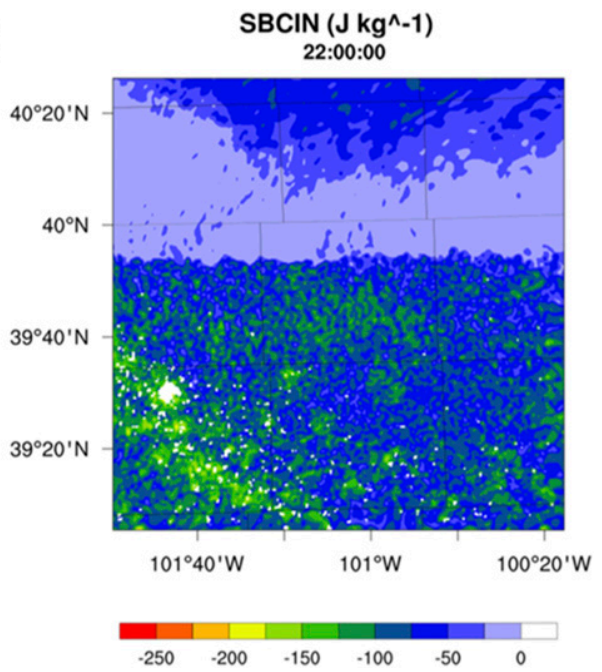

FIG. 16. Simulated (a) SBCAPE and (b) SBCIN at 2200 UTC.

MAHTE, volume-averaged vertical advection is calculated within a volume defined by the $15 \mathrm{~km} \times 15 \mathrm{~km}$ areas used previously (Fig. 10) and over a depth extending from the lowest model grid point to a height of approximately $375 \mathrm{~m}$. This height was selected so that the volume would be contained within the stable boundary layer that existed early in MAHTE formation. Initially, average vertical advection for both volumes is
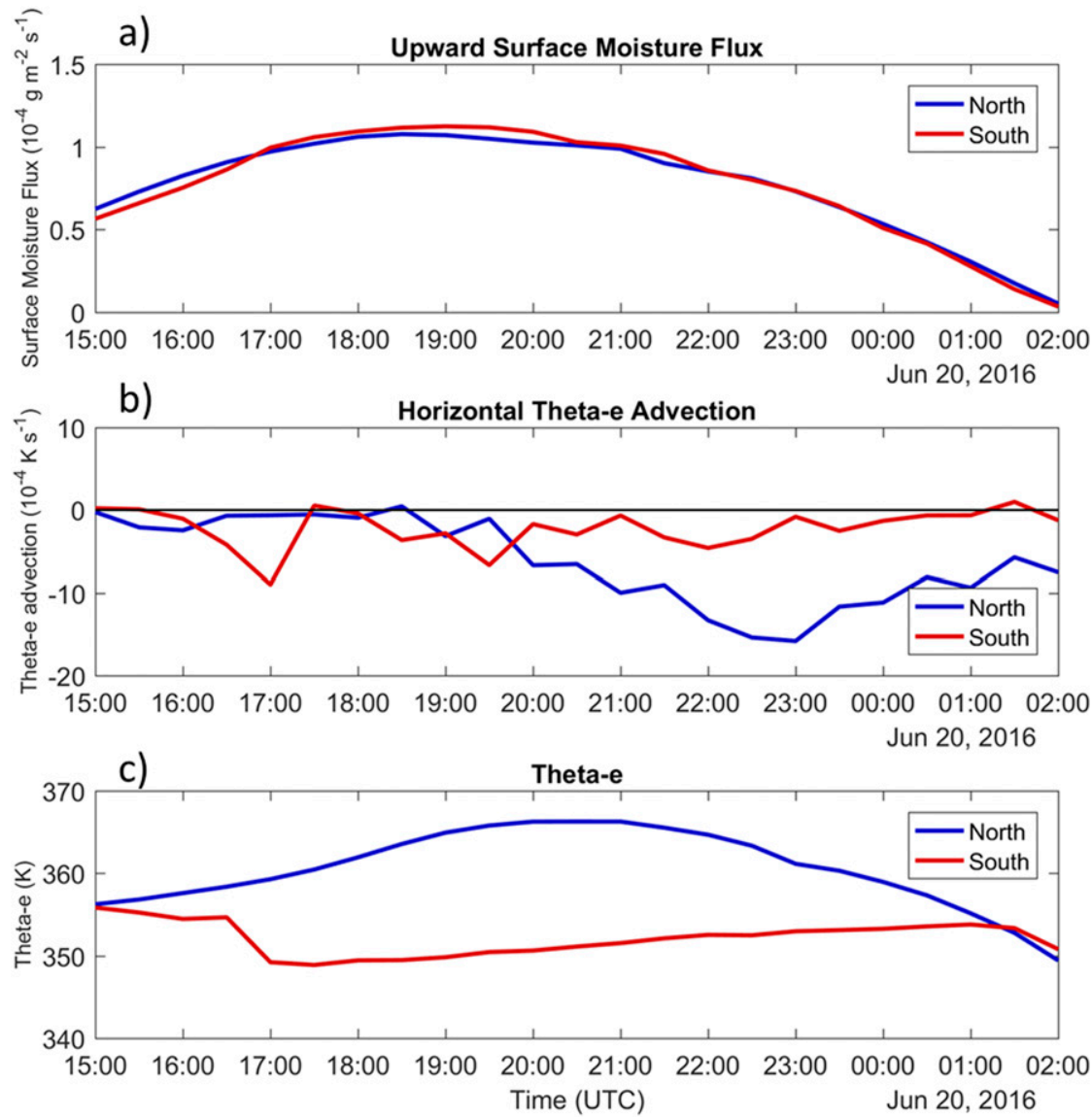

FIG. 17. Area averages of (a) upward surface moisture flux $\left(10^{-4} \mathrm{~g} \mathrm{~m}^{-2} \mathrm{~s}^{-1}\right)$, (b) 2-m horizontal $\theta_{e}$ advection $\left(10^{-4} \mathrm{~K} \mathrm{~s}^{-1}\right)$, and (c) $2-\mathrm{m} \theta_{e}(\mathrm{~K})$ for north (blue) and south (red) of the front. 


\section{Cross Section of Vertical Velocity}

a) 14:00:00 UTC

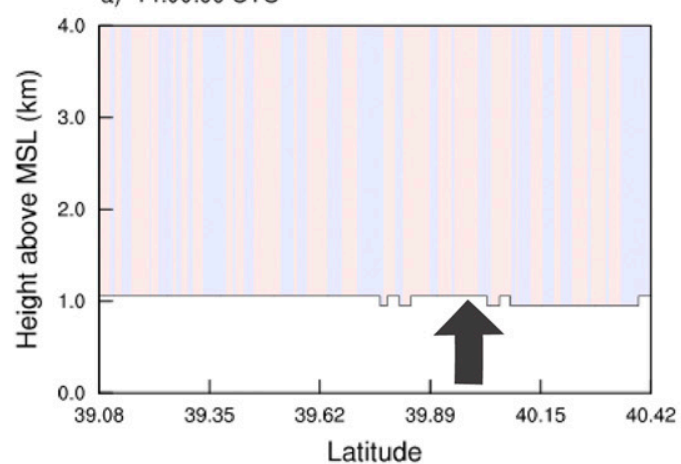

c) 18:00:00 UTC

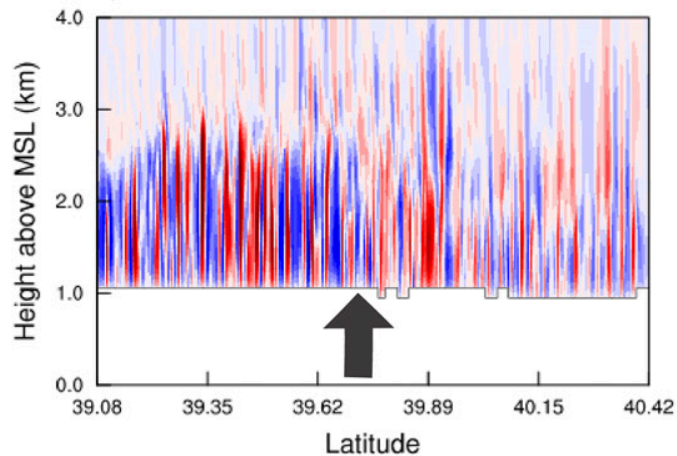

e) 22:00:00 UTC

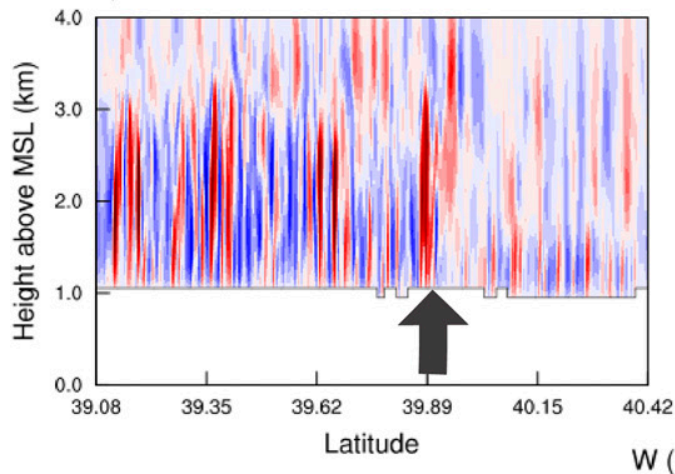

b) 16:00:00 UTC

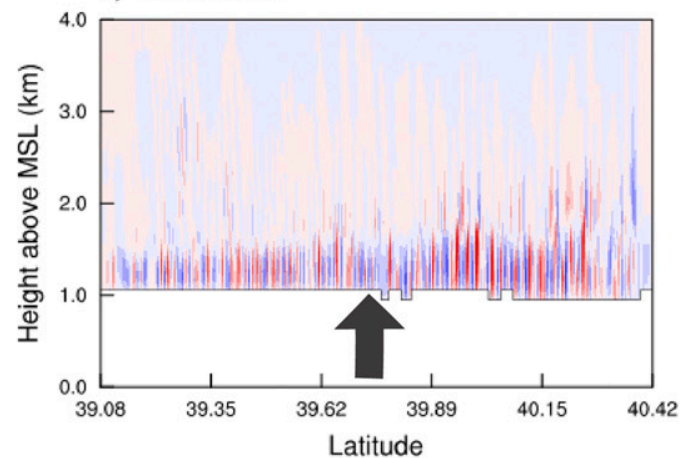

d) 20:00:00 UTC

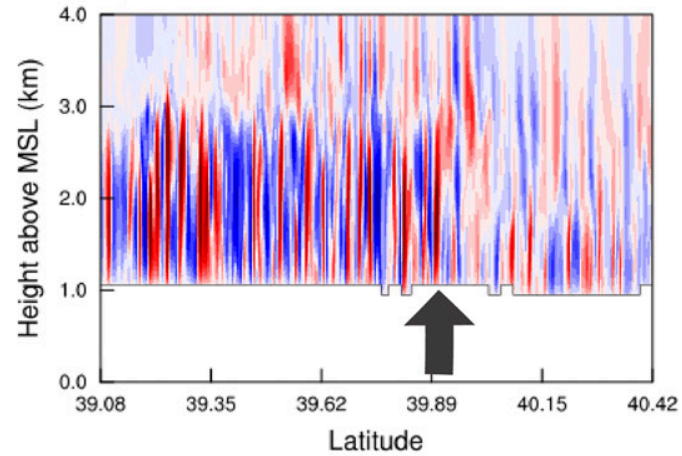

f) 00:00:00 UTC

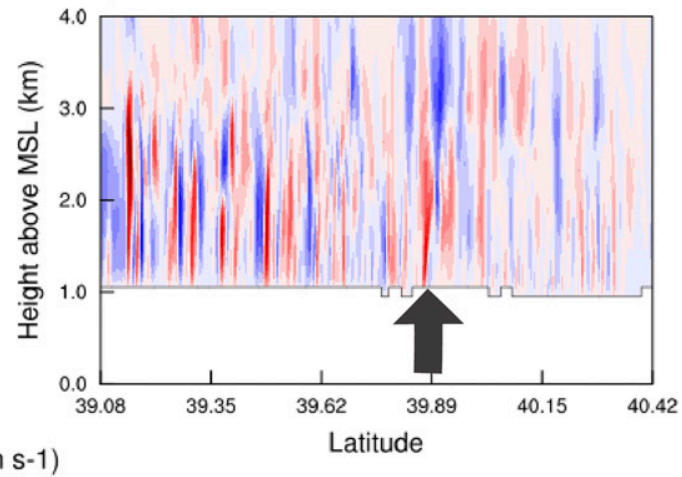

$\begin{array}{llllllllllllllll}-3.5 & -3 & -2.5 & -2 & -1.5 & -1 & -0.5 & 0 & 0.5 & 1 & 1.5 & 2 & 2.5 & 3 & 3.5\end{array}$

FIG. 18. South-north vertical cross sections of simulated vertical velocity ( $\mathrm{m} \mathrm{s}^{-1}$ ) for (a)-(f) 1400 to 0000 UTC. The approximate location of the front is indicated by the black arrow.

near zero (Fig. 19a), as vertical velocities are near zero (Fig. 18a). By 1600 UTC, a CBL has developed, and vertical mixing has increased (Fig. 18b), leading to downward transport of lower- $\theta_{e}$ air in the southern volume (Fig. 19a). This produces a reduction in average 2-m $\theta_{e}$ to the south of the cold front (Figs. 10c, 13c, 19b). At 1730 UTC, average vertical advection of $\theta_{e}$ in the warm sector decreases to zero due to the reduction of the initial vertical gradient of $\theta_{e}$ as the boundary layer becomes well mixed. After 1730 UTC, average vertical advection of $\theta_{e}$ in the warm sector becomes positive due to the slow increase of $\theta_{e}$ observed at the surface beginning at this time (Fig. 14). In contrast, vertical motions are both weaker and shallower within the MAHTE (Fig. 18) where volume-averaged vertical advection becomes positive shortly before 1600 UTC (Fig. 19a), likely due to increasing $\theta_{e}$ at the surface. Thus, as a consequence of reduced mixing in the cold air north of the cold front, the downward transport of lower $\theta_{e}$ from the EML into the cold air mass is reduced. Therefore, 

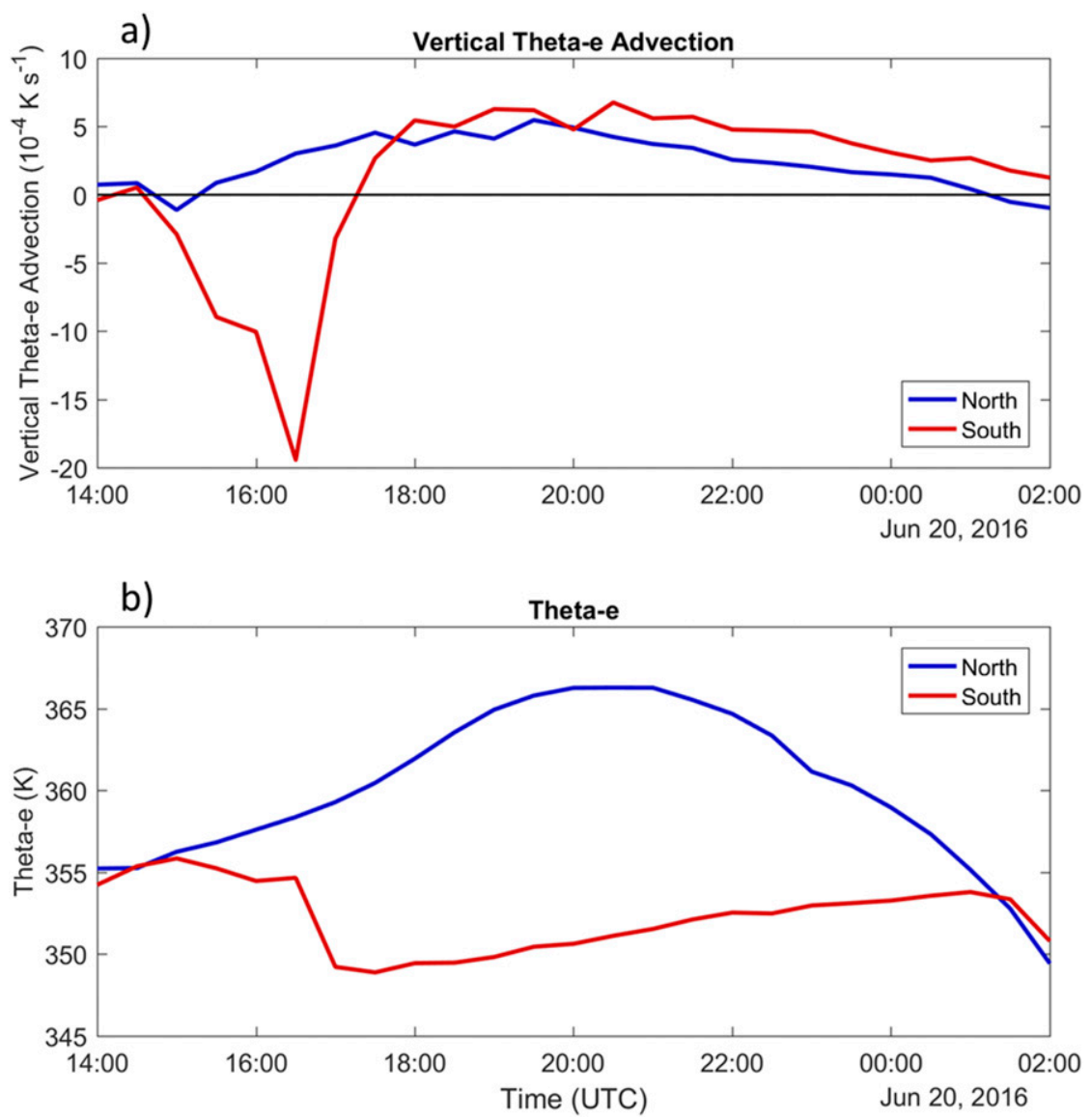

FIG. 19. (a) Averaged vertical advection of $\theta_{e}\left(10^{-4} \mathrm{~K} \mathrm{~s}^{-1}\right)$ and (b) averaged 2-m $\theta_{e}(\mathrm{~K})$ for north (blue) and south (red) of the front.

unlike the air mass south of the front, within the MAHTE, the negative $\theta_{e}$ tendency associated with vertical advection does little to mitigate increases in $\theta_{e}$ due to insolation-driven sensible heat fluxes. This process is summarized in Fig. 20.

Airmass modification through cross-boundary differences in vertical advection of $\theta_{e}$ bears resemblance to one of the processes responsible for the formationamplification of drylines. However, dryline formation is not synonymous with MAHTE formation. Most fundamentally, a MAHTE describes an air mass, while a dryline describes a boundary. However, the distinction becomes less obvious if dryline formation is essentially treated as modification of the associated air masses. Nevertheless, the small scale of a MAHTE makes it unique from the canonical moist air mass associated with a dryline. Moreover, while conceivable that preexisting airmass boundaries, such as cold fronts, warm fronts, or outflow boundaries, could transition into a dryline, this necessitates a diurnally varying frontal evolution that seems unnecessarily complex. Thus, as far as MAHTEs are concerned, we advocate for conceptualizing these as a unique air mass and not as transitions of an existing boundary into a dryline.

\section{Summary and conclusions}

A MAHTE along a synoptic cold front in northwest Kansas on 20 June 2016 was the focus of an investigation of MAHTE characteristics and mechanisms of formation. Observations showed that the MAHTE was approximately $40-50 \mathrm{~km}$ wide, with maximum $\theta_{e}$ located $2-5 \mathrm{~km}$ on the cold side of the cold front and approximately $15-20 \mathrm{~K}$ higher than observations within the warm environment. The highest values of $\theta_{e}$ within the MAHTE were observed to be collocated with the highest dewpoint temperature. Estimates of SBCAPE within the MAHTE indicate that it may have been $2000-3000 \mathrm{~J} \mathrm{~kg}^{-1}$ higher than in the warm sector.

WRF simulations of the MAHTE faithfully reproduce many characteristics of the observed MAHTE. The most significant process driving MAHTE formation was found to be cross-front differences in vertical $\theta_{e}$ advection. 

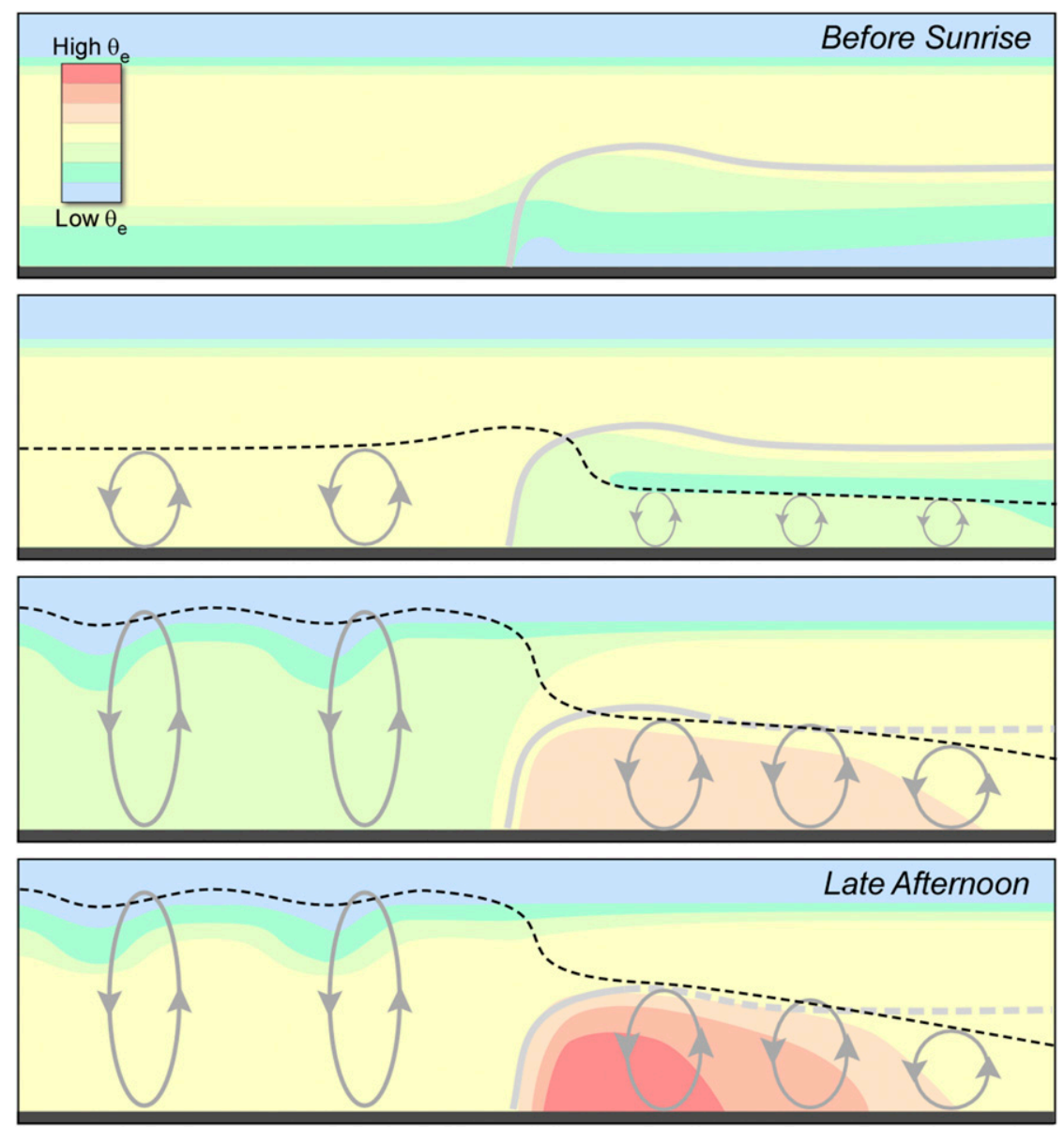

FIG. 20. Conceptual illustration of the formation of the 20 Jun 2016 MAHTE. Panels (top to bottom) represent the evolution of $\theta_{e}$ in cross section. The thick gray curves represent the cold front, the black broken curve represents the top of the CBL, and ellipses with arrows represent convective mixing.

Within the warmer air mass, vertical mixing during the late morning and afternoon was stronger and deeper than on the cold side of the front, resulting in a decrease of $\theta_{e}$ through advection in the warm air mass and insulation of moisture within the MAHTE. This allowed largely unmitigated insolation-driven increases in $\theta_{e}$ within the cold air. Horizontal $\theta_{e}$ advection contributed to the reduction in $\theta_{e}$ south of the front but followed the large tendency from vertical advection. Surface moisture fluxes could not explain the cross-boundary differences in $\theta_{e}$ tendency and thus are an unlikely explanation of MAHTE formation. Similar to observations, simulated SBCAPE was approximately $3000 \mathrm{~J} \mathrm{~kg}^{-1}$ higher within the MAHTE relative to the warm sector.

Future work aims to expand the focus to include cases of MAHTEs along thunderstorm outflow boundaries. Additionally, idealized simulations will be conducted spanning an experiment parameter space that will facilitate the identification of environmental conditions favorable for MAHTE formation.

Acknowledgments. This work was supported by the National Science Foundation Grants AGS-1542760 and OIA-1539070. Simulations conducted for this work utilized the Holland Computing Center of the University of Nebraska, which receives support from the Nebraska Research Initiative. We thank George Limpert for his assistance with obtaining data used for the WRF simulations and for helping to set up the WRF Model for analysis. We would also like to thank Curtis Riganti for his help with the boundary relative transformation code, as well as Matthew Van Den Broeke and Clint Rowe for suggestions to improve the original draft of this work. Thanks also go to Tony Reinhart for his initial work on MAHTEs, Jason Keeler for numerous discussions on MAHTE concepts, and the students who worked with 
the Severe Storms Research Group to collect the data used in this analysis.

\section{REFERENCES}

Bannon, P., 2002: Theoretical foundations for models of moist convection. J. Atmos. Sci., 59, 1967-1982, https://doi.org/ 10.1175/1520-0469(2002)0591967:TFFMOM2.0.CO;2.

Blumberg, W. G., K. T. Halbert, T. A. Supinie, P. T. Marsh, R. L. Thompson, and J. A. Hart, 2017: SHARPpy: An open-source sounding analysis toolkit for the atmospheric sciences. Bull. Amer. Meteor. Soc., 98, 1625-1636, https://doi.org/10.1175/ BAMS-D-15-00309.1.

Burghardt, B. J., C. Evans, and P. J. Roebber, 2014: Assessing the predictability of convection initiation in the high plains using an object-based approach. Wea. Forecasting, 29, 403-418, https://doi.org/10.1175/WAF-D-13-00089.1.

Charba, J., 1974: Application of gravity current model to analysis of squall-line gust front. Mon. Wea. Rev., 102, 140-156, https://doi.org/10.1175/1520-0493(1974)1020140: AOGCMT2.0.CO;2.

Chen, L., Z. Ma, and X. Fan, 2012: A comparative study of two land surface schemes in WRF Model over eastern China. J. Trop. Meteor., 18, 445-456.

Coniglio, M. C., J. Correia, P. T. Marsh, and F. Kong, 2013 : Verification of convection-allowing WRF Model forecasts of the planetary boundary layer using sounding observations. Wea. Forecasting, 28, 842-862, https://doi.org/10.1175/ WAF-D-12-00103.1.

Dudhia, J., 1989: Numerical study of convection observed during the Winter Monsoon Experiment using a mesoscale two-dimensional model. J. Atmos. Sci., 46, 30773107, https://doi.org/10.1175/1520-0469(1989)0463077: NSOCOD2.0.CO;2.

Emanuel, K., 1994: Atmospheric Convection. Oxford University Press, $580 \mathrm{pp}$.

Gilmore, M. S., and L. J. Wicker, 2002: Influences of the local environment on supercell cloud-to-ground lightning, radar characteristics, and severe weather on 2 June 1995. Mon. Wea. Rev., 130, 2349-2372, https://doi.org/10.1175/1520-0493(2002) 1302349:IOTLEO2.0.CO;2.

Goody, R., 2000: Sources and sinks of climate entropy. Quart. J. Roy. Meteor. Soc., 126, 1953-1970, https://doi.org/10.1002/ qj. 49712656619 .

Grant, L. D., and S. C. van den Heever, 2016: Cold pool dissipation. J. Geophys. Res. Atmos., 121, 1138-1155, https://doi.org/ 10.1002/2015JD023813.

Groenemeijer, P., U. Corsmeier, and Ch. Kottmeier, 2011: The development of tornadic storms on the cold side of a front favoured by local enhancement of moisture and CAPE. Atmos. Res., 100, 765-781, https://doi.org/10.1016/ j.atmosres.2010.10.028.

Guyer, J. L., and R. Ewald, 2004: Record hail event-Examination of the Aurora, Nebraska supercell of 22 June 2003. 22nd Conf. on Severe Local Storms, Hyannis, MA, Amer. Meteor. Soc., 11B.1, https://ams.confex.com/ams/11aram22sls/techprogram/ paper_82087.htm.

Langhans, W., and D. M. Romps, 2015: The origin of water vapor rings in tropical oceanic cold pools. Geophys. Res. Lett., 42 , 7825-7834, https://doi.org/10.1002/2015GL065623.

Lowe, R. J., P. F. Linden, and J. W. Rottman, 2002: A laboratory study of the velocity structure in an intrusive gravity current. J. Fluid Mech., 456, 33-48, https://doi.org/ 10.1017/S0022112001007303.

Markowski, P., and Y. Richardson, 2010: Mesoscale Meteorology in Midlatitudes. Wiley-Blackwell, $407 \mathrm{pp}$.

Mlawer, E. J., S. J. Taubman, P. D. Brown, M. J. Iacono, and S. A. Clough, 1997: Radiative transfer for inhomogeneous atmosphere: RRTM, a validated correlated-k model for the longwave. J. Geophys. Res., 102, 16663-16682, https://doi.org/ 10.1029/97JD00237.

Morrison, H., G. Thompson, and V. Tatarskii, 2009: Impact of cloud microphysics on the development of trailing stratiform precipitation in a simulated squall line: Comparison of oneand two-moment schemes. Mon. Wea. Rev., 137, 991-1007, https://doi.org/10.1175/2008MWR2556.1.

Okalebo, J., R. J. Oglesby, S. Feng, K. Hubbard, A. Kilic, M. Hayes, and C. Hays, 2016: An evaluation of the Community Land Model (version 3.5) and Noah land surface models for temperature and precipitation over Nebraska (central Great Plains): Implications for agriculture in simulations of future climate change and adaptation. Climate Change Adaptation, Resilience and Hazards, W. Filho et al., Eds., Springer, 21-34, https://doi.org/ 10.1007/978-3-319-39880-8_2.

Pauluis, O., and I. M. Held, 2002: Entropy budget of an atmosphere in radiative-convective equilibrium. Part II: Latent heat transport and moist processes. J. Atmos. Sci., 59, 140-149, https://doi.org/10.1175/1520-0469(2002)0590140: EBOAAI2.0.CO;2.

Peixoto, J. P., A. H. Oort, M. de Almeida, and A. Tomé, 1991: Entropy budget of the atmosphere. J. Geophys. Res., 96, 10 981-10 988, https://doi.org/10.1029/91JD00721.

Rasmussen, E. N., J. M. Straka, R. Davies-Jones, C. A. Doswell, F. H. Carr, M. D. Eilts, and D. R. MacGorman, 1994: Verification of the Origins of Rotation in Tornadoes Experiment: VORTEX. Bull. Amer. Meteor. Soc., 75, 995-1006, https://doi.org/10.1175/ 1520-0477(1994)0750995:VOTOOR2.0.CO;2.

—, S. Richardson, J. M. Straka, P. M. Markowski, and D. O. Blanchard, 2000: The association of significant tornadoes with a baroclinic boundary on 2 June 1995. Mon. Wea. Rev., 128, 174-191, https://doi.org/10.1175/1520-0493(2000)1280174: TAOSTW2.0.CO;2.

Raymond, D. J., 2013: Sources and sinks of entropy in the atmosphere. J. Adv. Model. Earth Syst., 5, 755-763, https://doi.org/ 10.1002/jame.20050.

Riganti, C. J., and A. L. Houston, 2017: Rear-flank outflow dynamics and thermodynamics in the 10 June 2010 Last Chance, Colorado, supercell. Mon. Wea. Rev., 145, 2487-2504, https:// doi.org/10.1175/MWR-D-16-0128.1.

Ross, A. N., A. M. Tompkins, and D. J. Parker, 2004: Simple models of the role of surface fluxes in convective cold pool evolution. J. Atmos. Sci., 61, 1582-1595, https://doi.org/ 10.1175/1520-0469(2004)0611582:SMOTRO2.0.CO;2.

Schlemmer, L., and C. Hohenegger, 2016: Modifications of the atmospheric moisture field as a result of cold-pool dynamics. Quart.J. Roy. Meteor. Soc., 142, 30-42, https://doi.org/10.1002/ qj. 2625 .

Simpson, J. E., 1987: Gravity Currents in the Environment and Laboratory. Ellis Horwood Limited, 248 pp.

Skamarock, W. C., and Coauthors, 2008: A description of the Advanced Research WRF version 3. NCAR Tech. Note NCAR/TN-475+STR, 113 pp.

Skyllingstad, E. D., and S. P. de Szoeke, 2015: Cloud-resolving large-eddy simulation of tropical convective development and 
surface fluxes. Mon. Wea. Rev., 143, 2441-2458, https://doi.org/ 10.1175/MWR-D-14-00247.1.

Tewari, M., and Coauthors, 2004: Implementation and verification of the unified Noah land-surface model in the WRF Model. 20th Conf. on Weather Analysis and Forecasting/ 16th Conf. on Numerical Weather Prediction, Seattle, WA, Amer. Meteor. Soc., 14.2a, https://ams.confex.com/ams/ 84Annual/techprogram/paper_69061.htm.

Tompkins, A. M., 2001: Organization of tropical convection in low vertical wind shears: The role of cold pools. J. Atmos. Sci., 58, 1650-1672, https://doi.org/10.1175/1520-0469(2001)0581650: OOTCIL2.0.CO;2.
Wakimoto, R. M., H. Cai, and H. V. Murphey, 2004: The Superior, Nebraska, supercell during BAMEX. Bull. Amer. Meteor. Soc., 85, 1095-1106, https://doi.org/10.1175/ BAMS-85-8-1095.

Yokoi, S., M. Katsumata, and K. Yoneyama, 2014: Variability in surface meteorology and air-sea fluxes due to cumulus convective systems observed during CINDY/DYNAMO. J. Geophys. Res. Atmos., 119, 2064-2078.

Young, G. S., S. M. Perugini, and C. W. Fairall, 1995: Convective wakes in the equatorial western Pacific during TOGA. Mon. Wea. Rev., 123, 110-123, https://doi.org/10.1175/1520-0493(1995) 1230110:CWITEW2.0.CO;2. 